


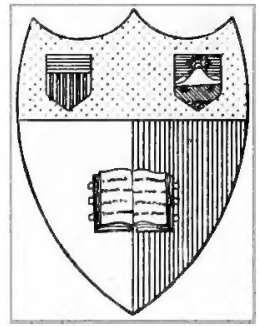

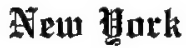

State Orallege of Agrirulture

At Garnell \#niuersity

3thuara, N. 11.

\section{Tíluxary}




\section{Cornell University Library \\ SF 487.8655}

Broilers and roasters, the specialties of ||||||||||||||||||||||||||||||||||||||||||||||||||||||||||||||

. I. I. I. 


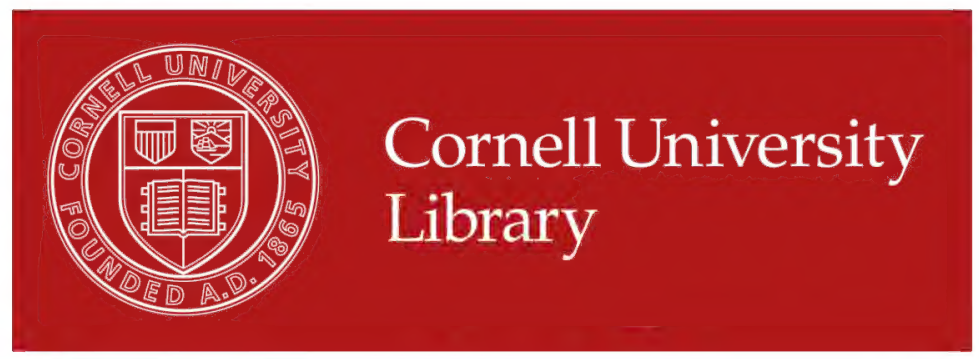

The original of this book is in the Cornell University Library.

There are no known copyright restrictions in the United States on the use of the text.

http://www.archive.org/details/cu31924003057712 
FARM-POULTRY SERIES No. 7.

\section{Broilers $\overline{\overline{\mathrm{AND}}}$ Roasters}

THE

Specialties of the Market Poultryman.

BY

\section{JOHN H. ROBINSON,}

Editor of Farm-Poultry. Author of "Poultry-Craft," etc.

\section{PRICE 50 CENTS.}

Published by

FARM POULTRY PUBLISHINO Co.,

Boston, Mass.

1905. 


$$
\text { COPÍRIGHTED ì }
$$

FARI-LOULTRY PUB. CO.

1904. 


\title{
Broilers AND RoAsters.
}

\author{
CHAPTER I.
}

\section{Some General Information About Market Poultry Culture.}

1. Why Only Broilers and Roasters are Considered.- This book will treat especially, and almost exclusively, of broilers and roasters because these are the two classes of market poultry in which one making a specialty of growing poultry (chickens) for market is interested. It might be said that broilers and roasters are the only chickens grown for market by specialists, for the business poultry keeper, whatever branches he follows, tries to work his surplus young stock into one or the other of these two channels of trade, while the entire product of "fowls," as old hens are classed on the market, may be said to be a by-product of egg farming, the hen, as a rule, not going to market until her owner feels that her days of profitable laying are over. The "capon" is a roaster. The "fry" of the west and south is, when a small fry, about the size of the largest broilers in demand in the eastern market. The large fry is not in special 
demand in the big markets, and what stock of this grade comes in is worked off as just "chickens" at a figure generally considerably lower than the price for the sizes most in demand. It is, perhaps, hardly necessary to say that the least salable sizes are not sent to the market by experienced growers. If for any reason they do not market their chicks as broilers they hold them until they will fill the bill as roasters.

2. What is a Broiler? - The dictionary definition, "a chicken, or the like, suitable for broiling," does not describe a broiler so that one who did not know what kind of a chicken is suitable for broiling is any the wiser for having consulted the dictionary. It is possible to broil and cook in this way very nicely chickens very much larger than are sold on the market as broilers, but that does not make such a chicken a broiler. The technically correct definition of this kind of "broiler" is a chicken or other fowl such as is in general demand for broiling. The difference in meaning is of no importance to the general public, but the would-be producer of broilers should have a clear appreciation of just.what he is going to produce, and why. His business is not merely to grow chickens especially adapted for broiling, but to grow thrifty good bodied chickens which are to be marketed at some one of the sizes in general demand for broiling. He must always look beyond his product to the market whence comes the demand which gives that product special value.

\section{The Sizes of Broilers the Market Calls for.-} The market demand today is for broilers of three sizes: Small broilers, large broilers, and squab broilers. The ordinary small broilers, the size most in demand during 
the greater part of the year weigh, when dressed, plucked, but undrawn, and with head and feet on, from two to two and onethalf pounds to the pair. They may weigh less or more, but this is the desirable range of weights; that is, a pound to a pound and a quarter apiece.

The desirable average weights for large broilers are three to three and one-half pounds to the pair; that is, a pound and a half to a pound and three-quarters apiece. They may go two pounds or more each, but when the desirable weights are exceeded they will not, as a rule, bring as high prices per pound, so that there is seldom gain, and may often be loss, by marketing these larger chickens as broilers.

Squab broilers have been in general demand for only a few years. They are small broilers weighing, a pound and a half to two pounds to the pair, three-quarters of a pound to a pound each. The demand for them is mostly confined to the latter half of the winter. The call for squab broilers seems to have begun with the willingness of caterers who found it difficult to get suitable game for banquets and like occasions to use broilers smaller than had previously been considered fit for the table, as a substitute for game. It is worth recording, as an item of interest to those engaged in producing squab broilers, that for some years there was a good deal of sentiment prejudicial to slaughtering chicks at that tender age expressed. It is also noteworthy that after the popularity of the squab broiler became assured, there arose for a little while some demand for still smaller chickens, and chickens only a few weeks old were served to epicures in search of novel edibles, but the public would have none of them. 
4. Where the Broilers Go.-The broiler grower will, perhaps, find it easier to conform closely to market requirements as to desirable sizes of stock, if he knows something of where his produce finally goes. Generally the grower sells to a dealer, so does not come in contact with the consumers. The large buyers of broilers are the high priced hotels and restaurants, the caterers who provide "swell spreads" for clubs, reunions, etc., and wealthy families who do a great deal of entertaining. It is customary to serve each guest with half a "broiler," or with a whole "squab broiler," the broiler forming but one course of the meal. So both because each guest would eat but a small amount of "chicken," and because it is economy to serve the smallest portion admissible, the larger broilers are not readily taken by this class of customers, except at practically the same price as smaller ones.

For tables where those who feel so disposed may eat their fill of broilers the large sizes would be preferred. It is not possible to give an idea of the relative proportion of the demand for ordinary broilers from public houses and private families, but the public houses take probably ninetenths of all the squab broilers marketed; and probably the greater part of the broilers of this size are taken for banquets or like special occasions. It is no uncommon thing during the season to hear of buyers from city commission houses and markets scouring the country in their vicinity for squab broilers, and frequently offering more for chicks barely up to the usual minimum weight than the grower could get for the same chicks two months later. 
What is a Roaster? - Here the dictionaries are hardly up to date in their description of a roaster as "an article or animal suitable for roasting, especially a pig," and in the various transpositions of the words of that definition (taken from the Standard Dictionary) in the other dictionaries. Roasting chickens are used so much more than roasting pigs that the word "roaster" today probably suggests chicken to many times more people than think of little pigs when they hear that word. A fowl suitable for roasting must be a young fowl about full grown, but still soft meated, and to roast satisfactorily must be moderately fat. Roasters are roughly classed as "small roasters" and "large roasters." By far the greatest demand is for small roasters weighing eight to ten pounds to the pair, though the demand for large roasters weighing as much apiece as these do to the. pair is steadily increasing. Singular as it may seem the production of large roasters is the most profitable branch of market poultry culture, duck growing alone excepted. The reasons for this will be discussed elsewhere.

\section{Broiler Growing as an Exclusive Business. -} Growing broilers on a large scale as a specialty began at Hammonton, N. J., nearly twenty years ago. Those first engaging in it there were mostly men whose regular occupation was fruit growing, gardening, or some such pursuit which left them some months of comparative leisure each winter. The always high prices for young chickens in late winter and early spring and the developments of artificial incubation and brooding seem to have suggested. broiler raising to some of these men as a possible profitable occupation for this period. Many tried it. Some made: 
it pay well; others doubtless made claims of profit that were exaggerated or wholly false. The industry became so popular locally that the fame of it spread far and wide. Many people went to Hammonton as the ideal location for broiler growing to locate there and "get rich quick." Many others went there to learn the business and go and establish themselves elsewhere. The boom was overdone at Hammonton. The inevitable reaction came, and for a time interest in broiler growing languished there, but the special adaptability of this occupation as an adjunct to the fruit and garden interests of that locality kept many interested, and though with the development of broiler culture elsewhere the town has lost much of its prestige as the broiler town, it is doubtless true as is sometimes stated, that more broilers are produced there now each year than when the boom there was at its height.

One immediate result of the boom at Hammonton was the building of large broiler plants in many other places. Anyone familiar with the current poultry literature of the last fifteen years can recall the names of a number of such plants which have been built and equipped at large expense, and extensively advertised as "successful and netting very substantial profits each year until the owners' cash, credit or courage failed, and the abandonment of the project or a change to other lines of poultry culture came as a virtual confession of the untruth of the statements given out while the plant was in operation.

It is a matter of first importance to those. who may become interested in this subject to get the facts in regard to broiler culture as an exclusive industry, and not to allow themselves to be deceived by contrary claims which may be made for plants still in operation. Scores of such plants 
have been established, many of them on a large scale and with practically unlimited capital to back them. The total sum sunk in such investments in the last fifteen years is enormous, but there is not, so far as the writer is able to learn, today existing anywhere a single successful exclusive broiler plant. It is necessary to emphasize this fact, because through statements in old books and papers as well as through sensational stories which owners of new plants and not over-well informed or over-scrupulous writers and publishers from time to time give out, many people are deceived into investing capital in an undertaking which as an exclusive specialty cannot by any possibility prove profitable under present conditions of demand and supply.

A brief statement of the reasons for this will enable the reader to guard against being misled by stories of great success with broilers as an exclusive specialty.

Making a specialty of broilers will give a "living profit," that is, a profit which gives the grower compensation appropriate to the amount of the permanent investment and to his skill and labor, only for those broilers sold during the period of high prices, and the profits for broilers marketable during this period are not great enough to offset low profits at other times.

The great bulk of the broilers which come to market come from the general farms and from egg farms, and from the time these begin to be received in quantity until toward the end of the summer the market is amply supplied from these sources. Indeed they would during several months be a drug on the market were not the situation relieved by putting thousands of tons of the best into cold storage to be held until arrivals of fresh stock 
cease coming, or to be worked out at any time the demand indicates a profit atisfactory to the speculators who handle them. The cold storage supply as long as it lasts has a tendency to keep down prices on the new crop of broilers, so that between the advance of the beginning of the season of good supply of broilers from the farms, and the extenion of the period in which this supply of broilers is available by putting the daily surpluses into cold storage to be sold later, the season of attractive prices for the broiler specialist has been somewhat shortened, and is now so short that among those acquainted with the situation it is universally recognized as the fact that the profitable way to produce broilers is to make broiler growing one of the lines of a general poultry business.

\section{Broiler Growing as a Feature of a General} Poultry Business. - When conducted in this way broiler growing is profitable. This does not mean that it invariably pays a profit, or that anyone can make it pay. The broiler grower must understand his business, and there will be lean as well as fat years; but taking one season with another one who is fairly expert will make enough on what broilers he can produce and market during the period of high prices to make him feel satisfied with results of his work in this line. It fits into a time when unless one who has the equipment for artificial hatching and brooding is growing roasters, that equipment would be idle, and it works into a general business rather better than the growing of large roasters, because the broiler grower can have his broilers practically all out of the way before. beginning to hatch for stock purposes or to produce pullets for egg farming. Growing broilers in this way is worth 
the attention of anyone who has the equipment and cant spare the time.

\section{Growing Soft Roasters as an Exclusive:} Industry. - As has already been stated there is probably no branch of the production of market poultry products, except duck growing, that pays better than this. In what is known as the "South Shore" district of eastern Mass:tchusetts, the country about the towns of Norwell and Randolph, the production of 'soft roasters engages the attention of a great many people. A considerable proportion of them make it an exclusive business, and perhaps the majority of those interested in it limit their attention to. poultry to this one feature.

It is fortunate for those established in the business that the conditions under which it is carried on discourage attempts of people without either experience or capital to. engage in it. The equipment required to grow roasters on a large scale is not to be.put in for a few hundred dollars. The income comes almost wholly in about two months in early summer. During the remainder of the year expenses. are constant and sometimes heavy. A man must either have capital enough to go through most of the year without drawing money out of the business for current orliving expenses, or must have a reputation as a grower that will enable him to get the backing or credit he needs. to carry his crop of roasters until ready for market. If it were possible to make a beginning with as little capital as is often used for a start in other lines of poultry culture, or if there was any prospect of realizing a steady income. there would be many tempted to go into the business every year. As it is a good many people go into it who ought: 
to stay out, and in communities where growers sure of their position go steadily on year after year there is always a liberal sprinkling of newcomers who will hardly last a season, with here and there one who achieves a success which transfers him to the class of experts.

9. Growing Soft Roasters as an Adjunct to Other Occupation.- In the communities referred to above there are besides the successful and experimenta] plants which engage the time and attention of one or more men, many people who have time and facilities to grow a few hundred roasters annually, and who, living where the methods and profitableness of this line of work are well understood, take to it naturally. Some of them are strikingly successful, easily making additions to their regular incomes so substantial that within a few years they have given up other occupation, and are engaged exclusively in growing roasters. Some, as it is to be expected, fail and quit in discouragement. Others, probably the greater number, make enough to satisfy them, and continue growing roasters as a side 1ıne on such scale as their other ,engagemonts permit.

10. Growing Roasters as a Feature in a General Poultry Business. - It is in this way that most of the small roasters are produced. They come from the yards of breeders, from egg farms, and from the general farms. They are for the most part the surplus cockerels of the general purpose breeds raised and handled in the usual way, and marketed just as they approach sexual maturity. Considering the circumstances of their production, hey might be considered as a by-product rather than a specialty with their growers, though the profit in them, if they fill 
the demands of the best market, and are marketable at the right time, is good enough to make it worth while for those producing them to pay more attention to these points, and perhaps to make such changes in their general stock and system as will give them the most profitable by-product of soft roasters.

11. Combining Broilers and Roasters.-This combination does not appeal much to the large roaster specialist who had demonstrated to his own satisfaction that for one who is able to carry his stock through to roaster size the best prices paid for broilers are no temptation to dispose of growing stock at the broiler season. The grower of large roasters considers that his work is. practically done, that all ordinary risks are over when the chicken has reached broiler size, and nothing more remains but to keep it supplied with feed, keep the pulletsif possible from laying, and hope that the proportion of caponized cockerels that develop into slips will be small.The end and aim of all his plans and work is to have as. many large roasters as possible ready to market at the height of the season. With the broiler grower it is different. Many times he is in doubt as to whether to market a particular lot of chicks as broilers, or hold them to sell as. roasters, and many times he inclines to hold them, or would if he could handle them to advantage without interfering with his other departments. A lack of knowledgeof the easy and economical methods which prevail in the "soft roaster" section has no doubt kept many from holding chicks for roasters which would have been far more profitable if so handled. Then the ease of handling roasters, with the proper facilities, is such that it would be a comparatively simple matter for many a poultryman 
who gives some attention to the production of broilers, togrow a nice lot of roasters each season without adding much to his labors, or encroaching on his other stock. These things, mentioned in a general way in this preliminary chapter will be discussed in more detail in the appropriate connection in subsequent chapters.

\section{How About the Demand for and the Supply} of these Classes of Table Poultry ? - Notwithstanding occasional brief periods of overloaded markets, it may be truthfully said that the supply of extra choice table poultry, and even of ordinary good table poultry, is not adequate to meet the demand. We have to take the situation at large to determine a point of this kind, and we have also to consider the ranges and apparent tendencies of prices. For several years now all poultry of good grades has been higher than usual in the large centers of - population, and no grounds for anticipating an early or considerable reduction of values exist. It is clear to any student of market conditions that the demand increases faster than the supply increases, or is at all likely to increase, until facilities for instruction and training in poultry culture are much more efficient than at present. No prospective poultry grower need worry about the supply exceeding the demand, and leaving him without a satisfactory market for his products. What he needs to concern himself most about is to fit himself to produce good goods economically. When he can do that he can live comfortably through the period of reaction from a boom - if boom there should be; but there are at present no indications of a production that would glut the market for more than a very brief period. 


\section{CHA P TER II.}

\section{The Best Kinds of Stock and the Adapt= ability of Different Breeds to These Special Purposes.}

13. Points of a Good Broiler. - The ideal broiler is a plump, rather fine boned bird, meaty in every section. In most American markets a yellow skinned, yellow legged bird is preferred, and it is therefore policy for anyone producing large numbers of broilers to use yellow skinned stock. In the best markets - the markęts where prices are best - however, the color of skin and legs is not of so much importance as good quality of meat. To explain this fully it should be said that while a buyer in, say, Boston, would take a lot of yellow skinned broilers in preference to a lot of white skinned and white or black legged broilers, he generally would not object to a few chicks that were not yellow skinned in a lot which was on the whole satisfactory in color; while in case the yellow skinned lot were of inferior quality he would probably give the other the preference. This point is one which need not give much concern to the grower, for not more than one or two in a hundred poultry keepers are likely to have a larger proportion of chicks of undesirable color characteristics 


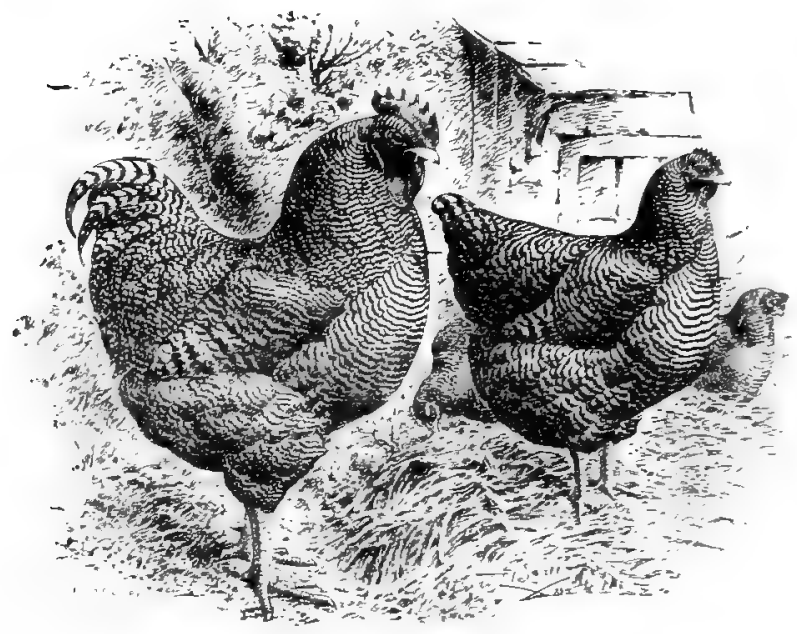

Barred Plymouth Rocks.

than will be readily taken by the market. Where growers fail oftenest is in the use of breeding stock not capable of producing really good broilers and in loss of quality of meat through slow growth of chicks.

What has been said of color should be qualified with reference to squab broilers. Black or dark feathered chickens when killed for squab broilers have a blueness of the skin on some parts of the carcass which disappears as they grow older, but which at this stage renders it very uninviting in appearance.

A chick with black or dark pinfeathers, while it may be dressed clean when of a pound to two pounds weight is more difficult to make attractive looking than a chick with white or buff plumage in which the pinfeathers need not 
be so carefully removed. So the grower after some experience in dressing is apt to give the preference to stock which gives him no dark, pinfeathers.

The stickler for the whole truth and for absolutely clean picking may affirm that all stubs ought to be removed before the chick is eaten. Some even go so far as to say they prefer the dark pinfeathers, bccause then when a carcass looks clean they know that all stubs have been removed. Such considerations are not likely to appeal to the grower who makes part of his living from broilers.
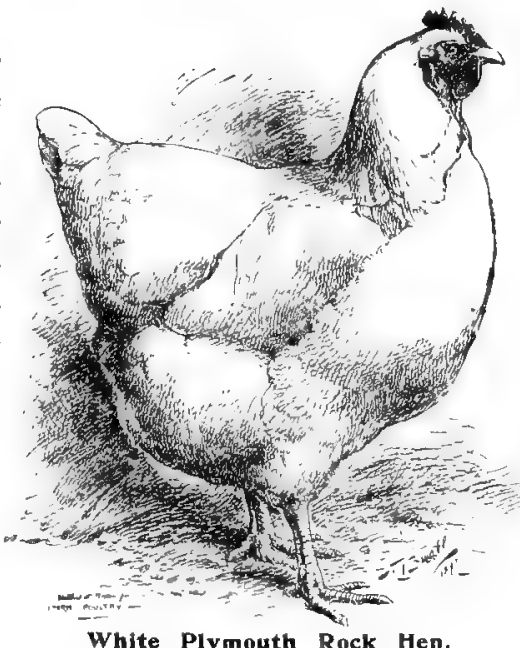

To the consumer what looks clean is clean, and the grower finds it to his interest to grow the kind of chicks that are easiest to make look clean.

\section{Kind of Stock From Which to Hatch Chicks} for Broilers. - It is quite customary, even among poultrymen making a good deal of a specialty of broiler growing, to consider stock not especially fit for any other breeding purpose good enough for the production of broilers. That this is wrong must be clear to anyone who gives the subject a moment's reflection. To get good broilers, chicks that have the desired conformation and grow 
rapidly, you must use for the parent stock birds of good development and vigor that were themselves quick growers. Very much of the unsatisfactory results in broiler growing are directly traceable to the use of unsuitable breeding stock. It is not necessary that there should be perfection or even excellence (from the fancier's standpoint) in color of the breeding birds selected. A white fowl though so

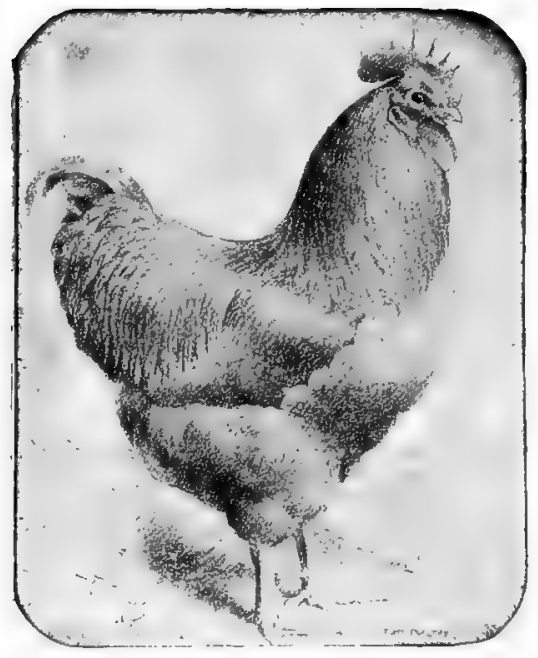

Buff Plymouth Rock Cock. liberally sprinkled with black ticking that a fancier would promptly reject it for any of his own purposes might be an excellent fowl for the production of broilers if good in shape and vigorous. It might have a poor comb, or discolored earlobes, or any one or more of numerous superficial faults that might be mentioned, yet be just as good for the production of broilers as though perfect in every one of these respects. But if it is narrow, or shallow bodied, or lacking in breadth or depth of breast, or too long in neck, body and legs to be symmetrical; if it is in any way deformed - crooked breasted, crooked backed, wry tailed, knock kneed - it should be rejected, for such blemishes make poor and unsightly carcasses. 
15. Points of a Good Roaster. - The ideal roaster might be described in almost the same words as used in the general description of the ideal broiler, but to complete the description in terms which will indicate the differences (besides difference in size) between them, we must say that greater length of body and breast is desirable in a roaster than is found in stock making the nicest looking broilers, and that the carcass of the roaster should show in every section a fuller rotundity more mature devel-. opment - than the broiler. Yellow skin and legs are, if anything, more generally demanded in roasters $\mathrm{than}$ in broilers, but the color of the feathers is of less importance, for the birds generally being

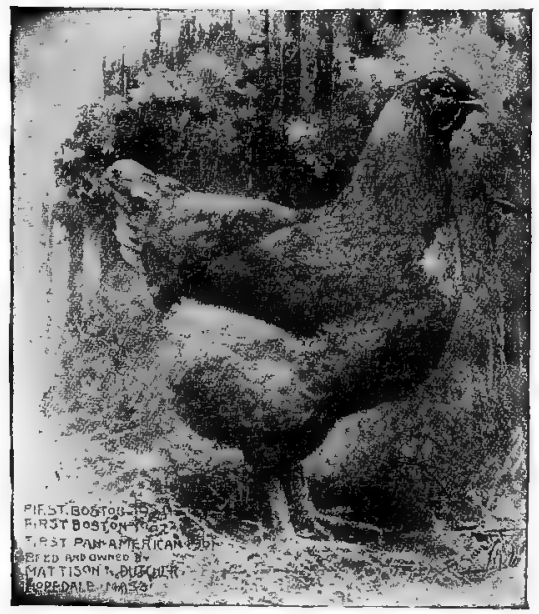

Buff Wyandotte Hen. dressed when well grown, are at that stage comparatively free from pinfeathers.

\section{Kind of Stock From Which to Hatch Chicks} for Roasters.-For small roasters quick growing stock is to be preferred; for large roasters, slow maturing stock, which remains soft meated until nearly full grown, is found most satisfactory by the growers who plan to have 
their stock marketable when prices are highest. The reason for this is the difficulty experienced in hatching chicks in mid-winter. If all chicks needed for the best large roaster

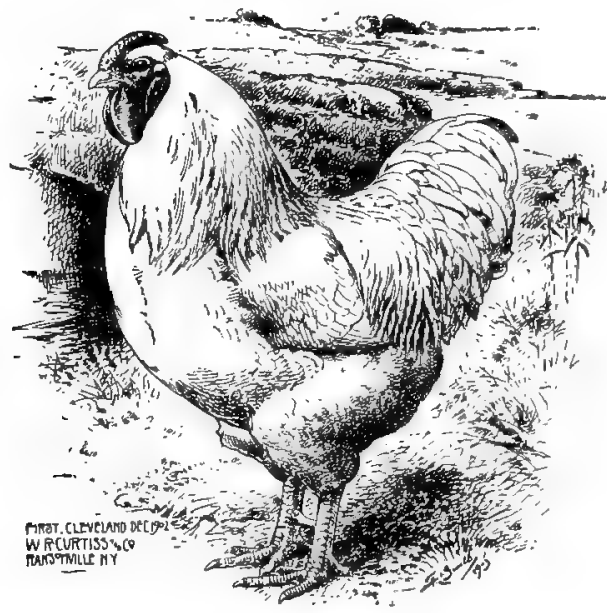

White Wyandotte cock.

trade could be hatched at that time, a s ingle kind of stock could easily be used to produce both small and large roasters. The same stock might not produce the best of both sizes, but the grower could use it to good advantage $f \circ r$ both demands by grading dressed poultry according to size, or by selling a lot as small roasters, or holding it to make large roasters, as seemed in each particular case most profitable. There is, of course, mure or less of this done, but the growers who make a specialty of large roasters find that to get out what chicks they need - to make sure of them - they must begin hatching in the fall, and use stock that matures slowly, as Asiatics, or the larger and slower maturing specimens of the American breeds.

\section{Using Mixed or Mongrel Stock to Produce} Market Poultry.- If stock that is not thoroughbred answers the description given for stock for the production 
of broilers and roasters there is no good reason why it should not be used. Stock that fills those requirements is, as a rule, pretty well bred, though not pure in blood. It certainly would be preferable to pure bred stock which did not fulfill the requirements. There is a great deal of such pure bred stock; in fact, the greater number of specimens. in the average flock of thoroughbred fowls would be unhesitatingly rejected by any grower alive to the importance of using breeding stock of the type he desired to reproduce in his market poultry. But while it is said that the breeder should, in his selection, be governed by the characteristics of the fowls rather than by their alleged pedigree, or want of definite pedigree, it must also be said that one is much more likely to find what he wants in thoroughbreds of the popular varieties, and if he cannot find what he wants, and has to develop it, he will attain his object much more rapidly by using thoroughbred stock. There is, of course,

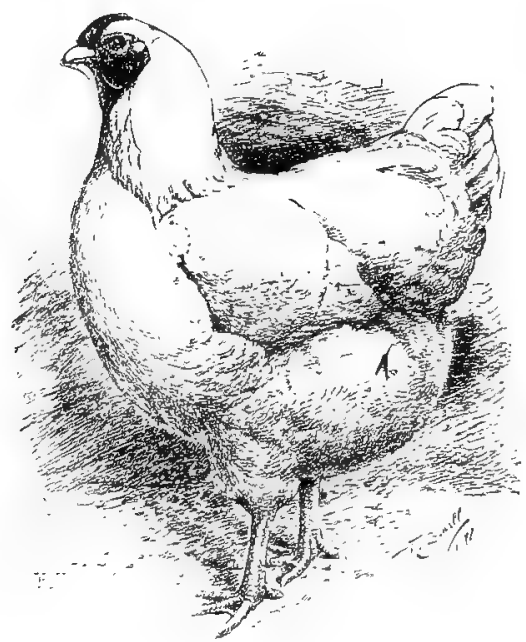

White Wyandotte Pullet. plenty of good stock excellently suited to the needs of the market poultry grower in the country, but the man who wants it does not always succeed in getting it, while the fanciers' lack of knowledge of just what is needed, or the 
disposition to work off on the "practical" grower anything he will not positively refuse to take, sometimes makes it very difficult for a market poultry grower to deal with them.

18. Should Broiler and Roaster Growers "Make" Their Own Eggs for Hatching? - Most of those growing them in large numbers either do not, or produce only a

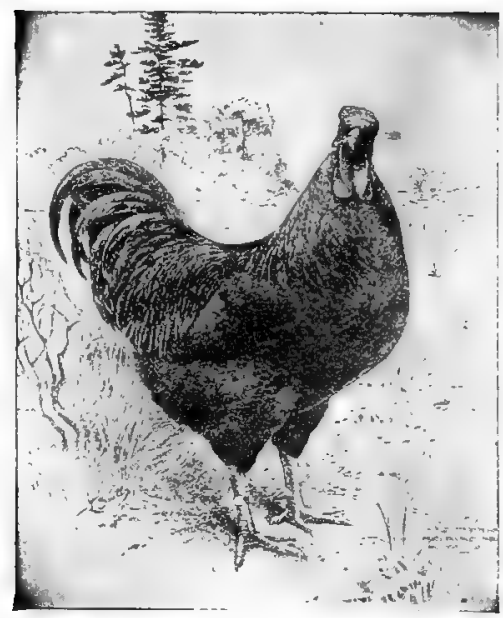

R. C. Rhode Island Red Cockerel. part of what they need. The practical difficulty in the way of a grower providing the eggs needed to hatch out a large number of chicks in winter is that it would require so large a stock of laying hens to produce the eggs needed that the grower cannot handle both branches of the business. The soft roaster growers have until very recently produced practically none of the eggs they used. Within a few years many of them have begun to build up stocks of breeding fowls from which to produce their own eggs, but there are few, if any, that do not still buy the most of the eggs they use. These eggs are bought from farmers throughout the vicinity. The large and steady demand for eggs for this purpose at a price considerably in advance of regular market prices is a strong inducement to 
farmers to keep stock of the kind the growers want, and to make every effort to have eggs in abundance and of good fertility at the time the growers want them. The success of those from whom he buys eggs in getting good fertility is an important factor in the success of the grower each season, and the utter inadequacy of the supply of eggs for those who want to grow soft roasters keeps a good many out of the business. A great many people going into the production of broilers buy eggs wherever they can get them. Though sometimes very sat- isfactory hatches are

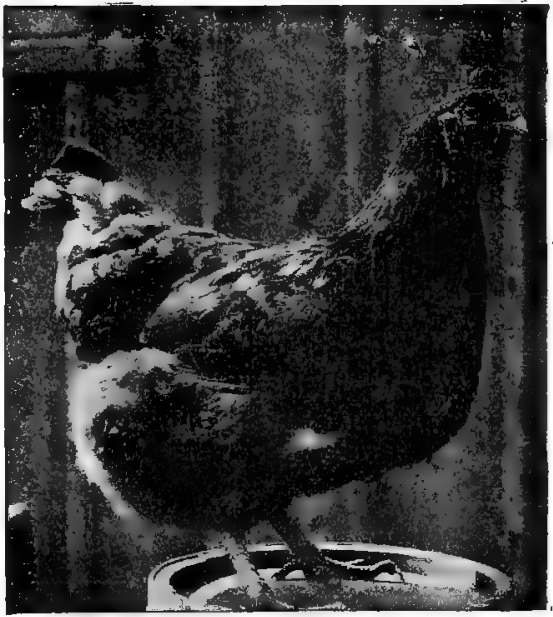

S. C. Rhode Island Red Hen. By Courtesy of F, D. Read. obtained from such eggs, the general results under such: conditions are so far from satisfactory that it is well for one contemplating broiler growing to make sure of a sufficient supply of eggs before he goes very far with his plans. If he keeps fowls himself he should know what he could reasonably expect to get from his own stock. In nearly every community there are a few people with a reputation for getting eggs at all seasons. These are the people to look up and contract with for the eggs one must buy. When either of the specialties we are discussing is run as a 


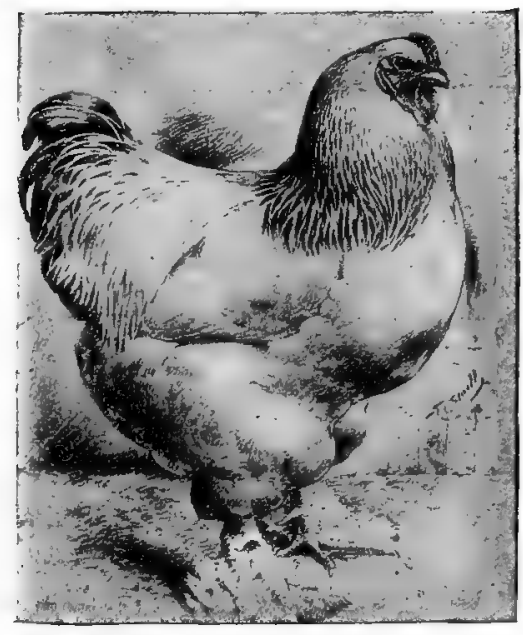

Light Brahma Cock.

branch of a poultry business the proposition is somewhat different. In $\mathrm{such}$ cases the general way is to adapt the plans for growing market poultry to the resources of the plant.

\section{Adaptability} of Different Breeds for Broiler a nd Roaster Growing. - Plymouth Rocks, Wy andottes and Rhode Island Reds, comprising the popular varieties of what is known as the "American class" of fowls are best suited to fill the bill of requirements for a fowl for producing both broilers and roasters. For the Canadian markets the Orpingtons, fowls of the same general type, but having flesh colored legs and white skin are generally preferred. Fowls of this size and type give plump broilers at any age, and good small roasters, while in all these breeds, but especially in the Plymouth Rocks. there are many stocks from which large roasters rivaling the Asiatics in size can be produced. In considering the question of breed or variety the reader should bear in mind that in discussing the varieties I refer to the characteristics of good typical specimens. The question of color of plunage $"$ an considered in 9913 and 14 . 
For large roasters the Asiatics, and especially the Light Brahmas, have the preëminence, the Brahmas being used almost to the exclusion of other breeds in the great soft roaster section. The Light Brahma used here is not as a rule quite up to standard size and weight; but as good average weight Brahmas for breeding purposes are always in demand it may be inferred that the general use of the smaller birds is due to the fact that they are more abundant rather than to their being more desirable. Indeed growers in that section say that the market demand for large birds is steadily increasing. Chicks of the Asiatic breeds do not as a rule make satisfactory broilers, but by a selection of stock of a plump and rather blocky type for breeding purposes one can get broilers from Asiatics that cannot be excelled.

The Mediterranean, Polish, and Hamburg breeds are rarely considered in treating of table poultry. Generally speaking, and speaking of the ordinary stocks of these varieties, for which, with the exception of the Minorca, there are no standards of weight required, each one of them lacks in one or more feature desirable. in market poultry.

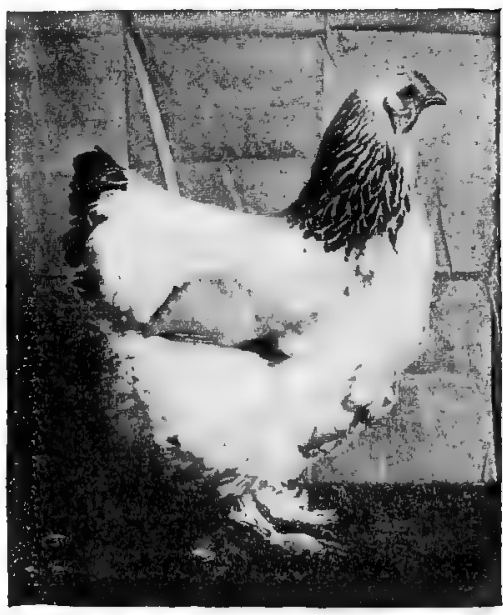

Light Brahma Hen. 
None of them but the Leghorns have the color of legs and skin almost universally demanded. In Leghorns, though the average stock is too small, there are many stocks of Leghorns of good size which will produce excellent broilers and small roasters. Indeed, I have had broilers from heavy bodied good sized Leghorns that grew faster than Plymouth Rock chicks under the same conditions make as nice looking broilers as I have ever seen, and were equal to any in quality. Such Leghorn stock is not common, however, and the most that can be said of the use of Leghorns for market poultry is that the largest types generally found make broilers that are fair as compared with those produced from average good Plymouth Rock and Wyandotte stock, while the largest and slowest maturing cockerels, if killed before their meat becomes hard, make very nice small roasters. Pullets of similar characteristics would also make nice small roasters, but the demand for them as layers is such that they are almost invariably reserved for that purpose. 


\section{CHAPTER III.}

\section{Location.- Land.-Methods in General.}

20. Location.-The question of location presents itself to a person interested in the production of market poultry in one of two forms. If he is already established in a place the question is: What branches of market poultry culture can be adapted to his circumstances; or if he desires to try a special branch, whether that branch can be pursued to advantage by one situated as he is. If he is free to locate himself in the place which seems best adapted to the line of work he proposes to follow, the question is to find such places and to select that which offers most advantages.

If either broilers or roasters are to be produced in considerable quantities, they can be sold to advantage only where there are considerable numbers of people who are not obliged to figure living expenses closely, who can and will buy what they want with little regard to price. As a rule this class is not numerous outside of the large citiesand their suburbs, except at health and pleasure resorts. The large cities give an all year round market for choice grades of market poultry. Resorts of the classes mentioned furnish excellent markets during their seasons. In all of 
these places the demand is on the whole so much greater than the supply that so far as the individual producer is concerned it is practically unlimited. The poultryman near such a market, or having shipping facilities which bring such a market near him, may plan for as large a product as he can handle without fear that his produce "ill prove unsalable, or salable only at a figure which leaves him little profit.

One who cannot reach such a market handily may still find it profitable to produce market poultry of different kinds to suit his local demand, which, though limited, is apt to be good in any prosperous town as long as production is in proper ratio to the demand. The grower who has access to large markets may find it to his advantage to make a specialty of some one kind of market poultry, or at appropriate seasons to produce as much of certain kinds as he can, but the poultryman who is dependent on a small narket must nearly always produce a little of each of the different kinds of poultry required for the best class of trade.

In selecting a location for a roaster plant, or for a plant to be devoted largely to broiler production, one must get near a large market, that is, within easy shipping distance of it, and, if possible, he should try to locate where there are others interested in the same special line of work. Where the market is limited, one must aroid competition; hut where the demand is so good that there is no competition between producers, except the natural rivalry to excel, one can have all the advantages of proximity to others engaged in the same business, without any of the disadrantages that sometimes attend such conditions. 
21. Land-How Much and What Kind?-For the production of broilers little land is required. During winter and early spring in northerly latitudes a little strip in front of the brooder house is all that can be used for the broilers, and even this can be used only in favorable weather. A great many small broilers are grown entirely indoors. Thus it will be seen that the installation of facilities for the production of thousands of small broilers would take only a small area of land, and broiler raising as an adjunct to other lines of poultry culture, or as an adjunct of some other business, can be carried on for a time on a site which gives room only for the necessary buildings.

The objection to establishing a plant on so limited a site is that the equipment cannot be used to good advantage for other purposes, and hence will stand idle or be used with little profit during a considerable part of each year. The broiler season is a short season. The same equipment used for early broilers can also be used for summer chickens if there is land enough to give them the large yards they should have. If one attempts to run both winter and summer chickens in the same house with such small yards as are adequate for winter conditions, he may do very well for a few seasons, but as the ground becomes tainted, his chickens cease to thrive, and usually the poultryman whose plant is in this condition struggles through several unsatisfactory seasons before he realizes just where the trouble lies.

For a large stock of roasters considerable land is required, for the stock is mostly about half grown when spring opens, and as it is not to be marketed for several months, the 
grower saves labor in caring for his fowls if he has land enough to spread them out well. Besides this, although the conditions of growing roasters admit of planting the land on which they have run after they are marketed, and growing late crops on it, if the land is heavily stocked with poultry year after year so much fertilizer is added to the land that planting it for a part of a season does not take the manure out of the soil fast enough to keep it as clean as desirable. Growers who have been established on farms which were ample as long as the land could take the manure almost invariably arrive within, at most, ten or twelve years, at the point where they feel they should have land enough to move the stock about more and give land that has been occupied for several seasons a rest for an cqual period. This is a point which it is hard to make either the beginner or one who has had a few successful seasons on a small plant appreciate to the extent of locating where he has two or three times as much land as he is likely to have occasion to use for some years to come. There are roaster plants producing 4,000 to 5,000 chickens it season on ten or twelve acres of land, but I do not think any of the proprietors of such plants would start again on so small a farm. With two, three or four times as much land one insures himself against being handicapped in the future for want of land room.

As to the kind of land, I think it may be said that the day when land that was not fit for any other purpose was considered just the thing for poultry is about gone by. Of , course no sensible person would go to the vicinity of a large city and buy high priced garden land to keep poultry on, but there is a medium between land of that class and 
land wholly unsuitable for cultivation. All things considered the most desirable land for a poultry farm is usually either light new land that when cleared will be suitable for tillage, or worn out tillage land. On either of these the poultry can be run much longer without change than on a rich soil or one that has been for some time in a good state of cultivation. Such lands are comparatively low priced, while if properly handled for poultry their value for other purposes may be so much increased that in the event of its becoming desirable for the poultryman to change his location he can get a fair price for his farm for farming purposes; while if he had established himself on land as unsuitable for growing crops of any kind as many of the poultry farms are, he would either have to remain there or sacrifice his land in order to make a change.

In buying land for a poultry farm, then, by all means buy land that crops can be grown upon. If you cannot farm the land yourself there are still few places where it would be advisable to start a poultry farm where one could not readily rent his extra land for at least enough to pay taxes on it and interest on the investment in it, and when the time comes that he needs more land or a change of Iand for his poultry, he has it.

\section{Broiler and Roaster Growers Use Artificial} Methods. - There are some growers of soft roasters growing a few hundred a year who hatch and brood their chickens with hens, getting most of the chicks out in the fall, but as a rule growers of both broilers and roasters use artificial methods of hatching and brooding. Indeed without the incubator and brooder these branches of the business could never have been developed as they have been. 
We need not discuss here whether it is better to use incubators and brooders than to use hens during spring and summer. It is the production of winter chickens that we are considering at present, and for this the artificial appliances are indispensable, the exception to their use noted above being one of the kind that proves the rule, for it is practicable only when operations are on a very limited scale. Fór late fall, early and mid-winter hatches broody hens cannot be obtained in sufficient numbers to hatch chicks on a large scale. For later hatches they may be, but the general tendency of hens is to wean their chicks early at that season, and hence the hens are most unreliable for brooding purposes at the season when it would be most desirable that they should remain long with their broods.

Hatching with hens and brooding artificially are sometimes combined, but rarely now where large numbers of chicks are produced out of the natural season. In short, wherever natural methods are used in the production of broilers and roasters it is because the venture is in the nature of a makeshift until arrangements for the use of artificial methods can be made. 


\section{CHA P T ER I V.}

\section{Buildings and Equipment.}

23. About Incubators. - This is one of the points on which one not familiar with the work of the different makes of incubators thinks it would be to his advantage to have specific advice from some disinterested person who did know something of what was being done with different machines. As an editor of a poultry paper, visiting many poultrymen every season, and in correspondence with many more, I am supposed by a great many people to be able to give such advice, and accused by some of being unwilling to do so because recommending one machine would result in the withdrawal of the advertising patronage of the manufacturers of other incubators. A number of such persons are not inclined to accept as sincere and truthful the statement $I$ frequently make in reply to such questions, that $I$ do not know. which is the best machine; that as nearly as I can judge from observations and reports there is little difference in the results obtained from different machines. One make of machine will suit one man better than any other. Another man just as successful in hatching will prefer a different machine. Many operators use two or, more makes of 
incubators at the same time, and find so little difference between them that they have no preference. One of the most expert operators I know told me he would be afraid to affirm that any one incubator would hatch better than another, because a number of times in his experience when one season's work seemed to show a certain machine superior to others run with it, the next season's work would entirely change the relative status of the machines used.

The explanation of this is that machines differing in principle and construction sometimes do their best work under quite different conditions. At one time the atmospheric conditions may be especially favorable to one of two machines, and it will do superior work. At another time conditions may be such that another machine will do better. Again, conditions may not be farorable to the best results possible from either machine, and they may work about alike.

Some men are on the whole equally successful with all the different machines they try, others will be very successful with one or two kinds of incubators, but always unsuccessful with other makes, whlie not infrequently we find people who never seem to acquire the knack of running any machine with satisfactory results. One can nerer tell what he can do or how he will succeed with any particular make of machine until be tries. Still, as the average man or woman with any mechanical knack at all can take almost any incubator and get fair results from it, no one need feel that time and money spent in experimenting with incubators is going to be wasted. It is with incubators as it is witl breeds, with houses, with methods (.f 
feeding, etc. There are many good ones, and there are also many people getting very good results though their equipment and methods are far from being all that is desirable, but however a person may begin sooner or later (if he stays) he works around to houses, breeds, methods, machines that suit him.

The most practical advice I can give in regard to choice of an incubator is to urge one beginning with them to buy not more than one or two incubators of medium capacity, say 100 to 200 eggs each before he is sure he can run that make of incubator satisfactorily, which means of course, beginning in a small way. That certainly is how anyone who has had no experience in artificial incubation should begin, yet every year a great many people who have never run an incubator and have it all to learn are equipping plants on which they start with from five or six to fifteen or twenty incubators, and while, as I have said, the differences between incubators as shown by general results is not considerable, the differences between operators as shown by experiences with the same machines are such that each operator wants to be sure which machines will suit him best before investing in many incubators, otherwise one is likely to find himself before long in the predicament of having to either use machines with which he cannot do his best work, or change machines at considerable expense, and perhaps temporary loss.

24. Brooding Systems and Brooders. - Much of what has been said of relative merits of incubators will apply equally to brooders, and to some extent to brooding systems, though of late years one system of brooding seems 
to be outranking the other in the favor of growers of winter chickens.

In artificial brooding there are two principal systems or methods-the continuous pipe system in which the chickens hover under pipes heated by hot water or steam, the pipes extending the length of the house and connecting with one large heater which supplies all the heat required, and separate " individual " brooders of a capacity of fifty to one hundred chicks each, having each its own lamp or stove heater.

In discussing the merits of the two systems it should be said first of all that the brooder "problem" has not yet been brought so near a satisfactory conclusion as has the hatching of chickens by artificial means. The two brooding systems have seemed to alternate in popular faror. Individual brooders came first. Then came the pipe system, and for awhile it was generally preferred. Then some great improvements in individual brooders were made, and the separate brooder did so much more satisfactory work, especially for the youngest chicks, that many growers adopted the plan of using what were called combination brooder houses in which pens for the youngest chicks were fitted with individual "nursery" brooders, while for chicks two to three weeks of age and uprard the less laborious system of pipe brooding was used. Within the last year or two the sentiment of the larger growers seems to have swung back to the pipe system. This is no doubt due to the improvements made in it, particularly the improvements in regulating the heat by means of electric thermostats and automatic drafts and damper adjustments of the heater. 
But though the pipe system now appears to have the preference with large operators, the individual brooder is, and no doubt will continue to be, very generally used by smaller operators and by those whose work is in an experimental stage, because the first cost is less, and it can often be adapted to existing house arrangements with little or no expense, when to install a pipe system would necessitate remodeling a building. The individual brooders being operated separately can be put in any convenient coop, shed, poultry house or other outbuilding, one here and one there, an advantage which appeals to one who does not want to make the changes in or additions to his plant which a pipe brooder house would require.

25. Incubator Cellars. - Incubators can be, and are successfully operated in all sorts of places, but every other arrangement for them is of a makeshift character, either a temporary arrangement, pending the construction of an - incubator cellar, or a substitute for the special incubator cellar, when for good reasons that cannot be built. When only one, or, at most, a few machines are to be operated, some substitute arrangement may be advisable, but when a greater number of incubators are to be operated a room constructed especially with reference to the requirements of this work should be considered a necessity, and wherever it is possible to set apart an appropriate room exclusively for incubation, though but a single machine is to be operated, the several advantages of so doing will more than repay the trouble and expense of making a special place for the incubator.

There is practical unanimity of opinion as to the best kind of room for incubators. A "cellar" about half 


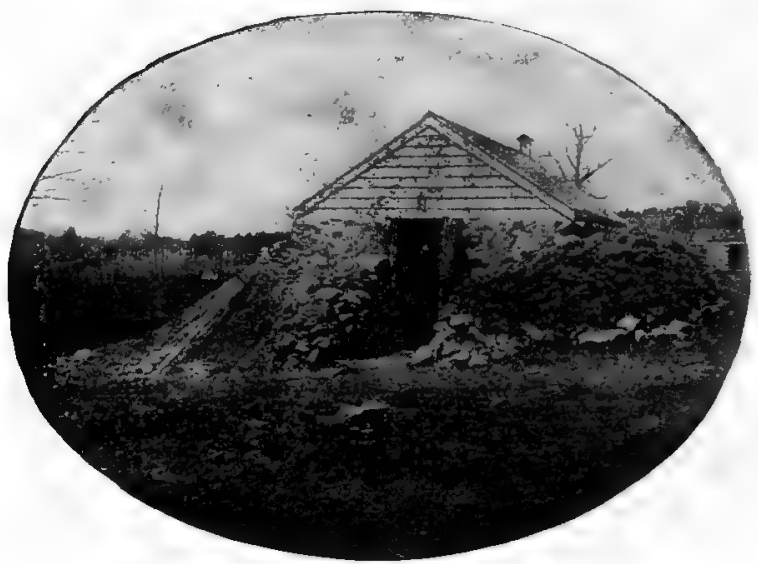

An Incubator Cellar, Banked to Eaves.

under ground provides most economically the conditions most favorable to the control of temperature, and to keeping the incubators in operation as far as possible from the effects of atmospheric changes or other external influences which might affect incubation.

Two illustrations of incubator cellars representing common plans are given herewith. These give external views of the cellars. It hardly seems necessary to give a diagram of the ground plan. In the first illustration the cellar, in a side hill, is banked up quite the full height of the walls. In the other, the cellar is built into a sort of natural curve in a bank, the north and west walls being wholly below the ground, while on the east and south sides the level of the ground outside is only about two feet above the cellar floor. Exact comparisons of the merits of the different cellars, as affected by the differences in construction, would be diffi- 


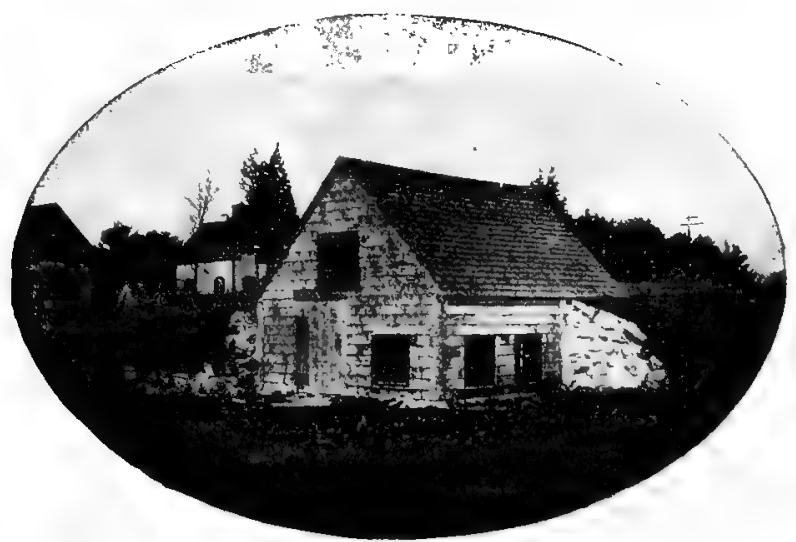

Incubator Cellar in Curve of a Bank.

cult, if not impossible. Probably, neither in case of the two cellars illustrated, nor in that of most of many others which, like them in general, but differing in slight particulars, might be illustrated, was there any careful and expert study and decision of the possible effects of slight deviations from other plans. As in all kinds of buildings, many minor features depend upon an undemonstrated idea, or even a mere whim of the builder, and no marked influence either for good or bad is traceable to these features.

The advantage of a room partly underground is that the temperature in it changes slowly and rarely reaches the extremes of either heat or cold which may prevail outside. It can make little material difference in this respect, whether the walls are banked half way up or a little more, or not evenly banked all around-provided there is not a large wall surface close to the incubators so exposed to. 
external heat and cold that its heating and cooling would affect the temperature about the machines. In the greater number of incubator cellars made where the ground is level or nearly so, the cellar is of such depth and the wall outside banked to such height that all wall surface adjacent to incubators is well protected outside. This leaves about two or two and a half feet of wall above the ground, an ample space for windows large enough for both light and ventilation. When a cellar is mostly below ground it is more difficult to ventilate it properly.

The reader may have noticed that in the second illustration the roof is high, leaving room for a loft with quite a good sized door above the line of the eaves. While in a small cellar where but few machines were run, this feature might not be of great importance, in a large cellar where many machines are operated, such a roomy loft helps the circulation of air in the cellar and so improves the ventilation both in the room and in the machines.

In determining the dimensions of his incubator cellar the poultry keeper should consider the shape as well as the number of the machines to be used in it. This is of importance even in case of a small cellar in which two rows of machines are to be placed, one along each side wall, because in such cases the limited space does not admit of such variation in the placing of the incubators, and sometimes a foot more one way or the other wonld mean a capacity of two more machines, or. ample room instead of an insufficient passage between the rows of machines.

Before leaving the subject of incubator cellars it will be in place to say a little more about running machines else- 
where. It has sometimes been claimed by manufacturers that certain machines could be run as well in an outbuilding as in a cellar, and this of course was a strong point in favor of such machines with those who did not want to put the machine in the house cellar or make a cellar especially for it. The facts about this matter as I have been able to get them from persons who are running machines entirely above ground, as well as from those who have tried machines in cellars and in buildings above ground simultaneously, are these: In a moderate and equable climate the room above ground may give as good results in general and without more labor than the cellar. In any place where considerable and sudden changes of temperature are frequent, the machines above ground require much closer attention and constant watching to guard against variations in the temperature of the egg chamber corresponding with the changes taking place outside.

26. Pipe Brooder Houses.-To attempt even a brief description of the many plans of pipe brooder houses that are now in use, and to present even in outline the many theories that have been more or less thoughtfully worked into them, would require a volume several times the size of this devoted exclusively to that one part of our subject. There would, however, be no great advantage in such a presentation of this subject. All the thought and study and experiment of many men, through many years, has made little difference in the houses. I think we may say no essential difference in principal features. They differ most in minor points, and these can be indicated in course of an account of one plan, or as supplementary to it, just as well as by giving full descriptions of many houses, 
repeating in each the descriptions of similar features. I will therefore describe first a brooder house which is one of the best models I have seen. In fact, in the ten years or more since it was first built the house has several times. been remodeled, and in its present form combines the results of years of experiment supplemented by lessons from the experience of many other operators of brooder houses.

If the reader will take a glance at the cross section in the cut below, at the ground plan on page 43 ,

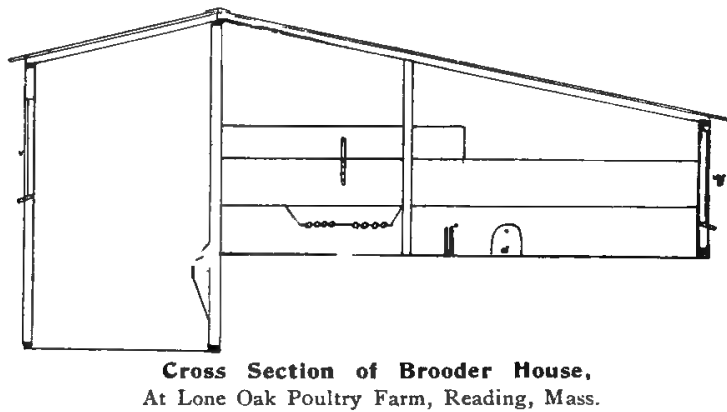

and the view of a part of the exterior of the house on page 47 , before I begin to explain the plan of the house and the reasons for its proportions, dimensions, and special features, he will better understand the allusions to each cut as there is occasion to refer to it in describing the house.

The house is low - only $3 \mathrm{ft}$. high from the foundation to the plate on the front or south side, with the apex of the roof only $5 \mathrm{ft}$. from the level of the pen floors. The floor of the passage in the rear of the pens is excavated to a depth of $2 \mathrm{ft}$. This arrangement reduces the amount of cubic space in the house, while still giving the operator 


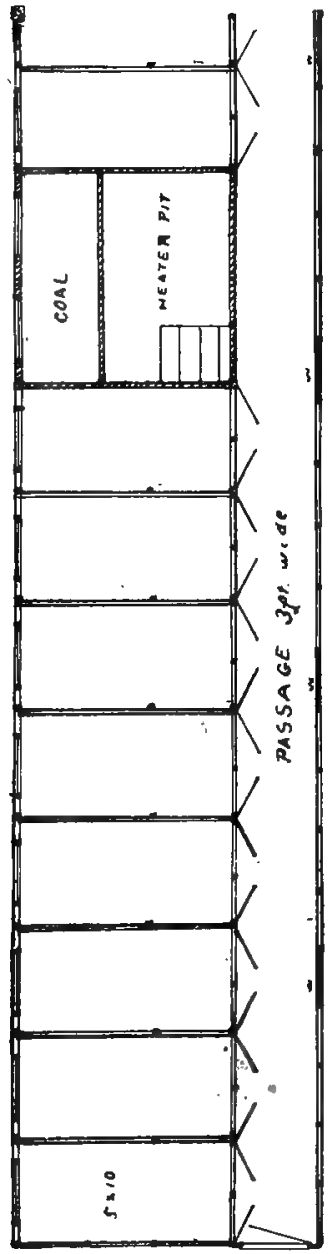

plenty of head room where he has to do his work, and at the same time makes his work easier, because the pen floors being at the height of the knee or a little above, he is saved a great deal of stooping, an item of economy in labor that does. not amount to much in caring for 'a few brooders, but means a great deal where many 造 hundreds or a few thousands. I.

The width of the house is. I $4 \mathrm{ft}$., the length of each pen being ro ft., and the inside width of the walk $3 \mathrm{ft}$. 9 in. Each pen is $5 \mathrm{ft}$. wide, and is lighted by a half window ( 6 ights $9 \times 12$ ) in the middle of the front of pen. At the sideof this window, as shown in the picture of the exterior of the house, is the small open-. ing givirig the chicks access. to the yard connecting with each pen. An inclined platform with strips of lath tacked across it to give the chicks foothold, extends in front of the house the full width of eacha 
pen, thus making it impossible for chicks to miss the way back to the brooder.

To support the roof and carry the partitions between the pens there are two upright pieces of $2 \times 3$ inch scantling for each partition, one at the passage, going from the floor of the passage to the apex of the roof, and one a little forward of the middle of the house, which goes from the floor of the pens to the roof; a few inches difference in the position of this upright, either backward or forward, would make no difference. The partitions between the pens are of solid boards two feet high. The 8 in. board extending from the passage half way forward is not a part of the partition, but a board used to place across the pen to keep the chicks close to the pipes when first put into the brooders. The two cleats a little forward of the short upright indicate the position of this board when in use. When not in use it is kept in the position shown in the diagram. An opening with cover swinging on a screw at the top is used to pass the chicks from pen to pen when that is desired. In some houses the partitions between the pens are carried higher with wire netting, but most operators would rather let the chicks mix a little as they get older than put in full partitions which, in a measure, interfere with such parts of the work as cannot be done from the passage, as cleaning the pen floors, etc.

The partition between pens and passage consists of two doors, light frames covered with inch mesh wire netting for each pen. The bottom edge of the door is on a level with the floors of the pen, the top edge with the top of the: partition between the pens. The $2 \times 3$ in. upright at the passage end of each partition being set with the 2 in. face 
to the passage, this is faced with a strip of $1 \times 3$ in. stuff to which the doors are hung with spring hinges. Midway between each two uprights at the passage is another I $\times 3$. in. piece against which these-doors or gates shut, and up the center of this strip reinforcing it and making a smooth finish where the doors meet is a strip I in. square. A. little below the level of the pen floors is a $2 \times 6$ in. strip resting on brackets of the same, extending the whole length of the pens to make a step for convenient entrance to the pens when it is necessary to go into them.

The floor of the pens is of cement, and the front wall: and ceiling are plastered. The north wall would also havebeen plastered, but having been ceiled with boards wher. the house was first built it was not necessary to alter that. The house was used for years with no ceiling overhead, and with a single wall in front, that being considered all that was necessary when individual brooders were used in a part of it, and the pipes were boxed up, making an enclosed brooder in each pen.

In the drawing on page $43 \mathrm{I}$ have indicated the heater pit in the middle of the house, though as a matter of fact in this house, used for a time as a combination house, there are two heater pits and two small heaters, one for each half of the house. When provision is made in: the plan for piping the entire house, the common way is to' have the heater pit in the center, and have one; and sometimes two, large heaters in it, either one of sufficient capacity to heat the whole house under any ordinary conditions. Only one heater is used at a time, the second being reserved for such emergencies as an extremely low temperature or the break down of the other heater. 
The heating arrangement need not be described in detail, for one who knows enough of plumbing to put in a heater himself does not need it, and one who has no practical knowledge of or skill in work of that kind could not do it by the specifications of an expert plumber, to say nothing of those of one-like the writer-whose knowledge of the subject goes no further than a fair comprehension of the theory and method applied. Heaters of various makes are

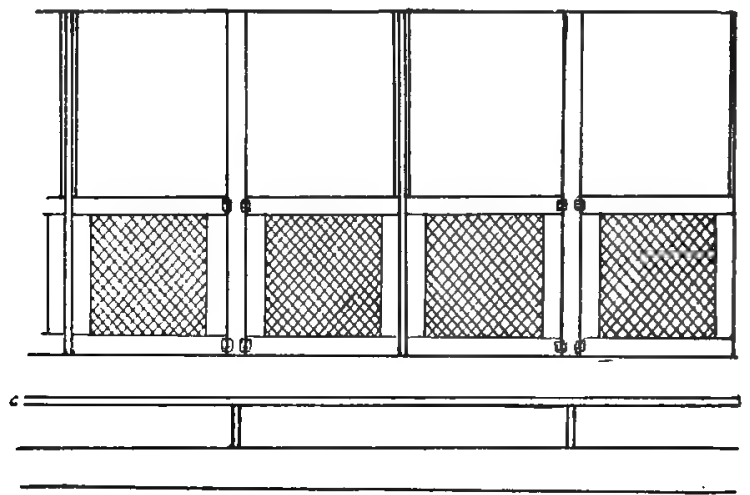

Partition Between Pens and Walk in Brooder Mouse,

At Lone Oak Poultry Farm.

to be had. As far as I can learn there is not a great deal of difference in them, and any practical plumber with -experience in fitting dwellings, shops and factories with hot water heaters can do the piping satisfactorily when shown the method of applying the heat, and told what is required.

The position of the pipes with reference to the other arrangements of the house is indicated in the cross sectional diagram on page 42 . There are two sets of four pipes 
each. Of each set two are flow and two return pipes, there being thus a constant circulation of water through them, and if the heater is of sufficient capacity an almost uniform temperature throughout the pipes. The pipes are not placed one above the other as is usual when plain pipes are used and attached to the walls in shops and factories, but are on the same level and 8 inches from the floors of

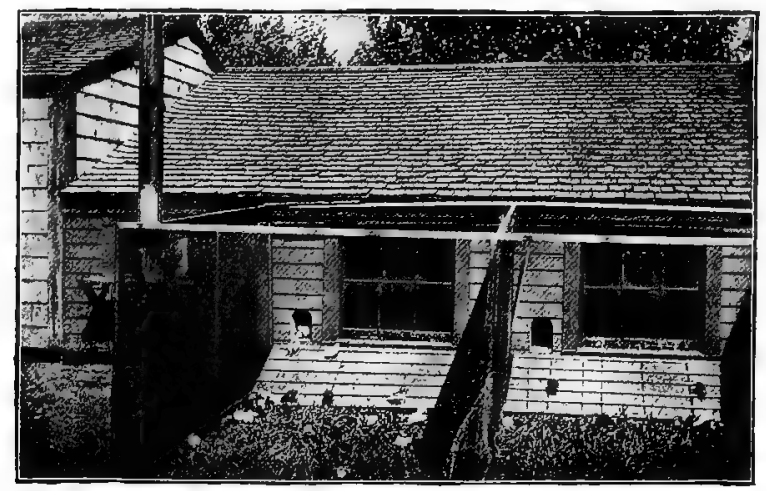

Vlew of Part of Exterior of Brooder House,

At Lone Oak Poultry Farm.

the pens. As indicated in the cut, a section of the bottom board in each partition is cut out to receive them, and after they are in position is carefully replaced.

In many houses the distance of the pipes from the floor varies, say from 4 or 5 inches in the pens near the heater to 8 or ro inches at the end of the house. The object of this is to have the height of the pipes from the floor vary to suit chicks of different ages and sizes. In other houses as in this the same object is gained in another way. The pipes are on a level, while the floor being of earth or sand, 
or as in the case of cement covered with several inches of sand, can be raised or lowered to give any required distance between the pipes and the floor within the limits fixed in the construction of the house. This of course does not necessitate the addition or removal of sand from the pen whenever a change in the level of the floor under the pipes is desired. All that is required is to heap the sand under the pipes for small chicks, and rake it away as the chicks grow larger. A distinct advantage claimed for this way of arranging for small chicks is that with several inclies of sand under the pipes, when that sand is heated through it retains the heat, and so the chicks are furnished both top and bottom heat.

27. Individual Brooders in Long Houses. - A house such as has just been described for pipe brooders is often used with individual indoor brooders. Many different arrangements of individual inside brooders are made. The entire floor may be on one level, the brooders placed three or four feet from the rear wall, just enough to leave a passage behind them, and far enough apart to give the required width to the pens in front of them, the distance, of course, varying according to the size of the brooder. Sometimes the arrangement is practically as just described, except that the passage back of the brooders is excavated as in the pipe brooder house described in the preceding section, and again the floor is excavated to the line between the brooders and the pens, that the brooders may be set enough lower than the pens to bring the floor of the hover on a level with the pen floors, and so avoid the use of an inclined runway to be traversed by the chicks in going back and forth between the hover and the pen. 
Another plan which seemed to please, for at least a time, the few who used it, but has never found favor generally, was to elevate the brooders two feet or more from the floor and build small pens, practically boxes, on the same level for the chicks to run in, there being passage room in the front of the house as well as in the rear. This was only, used in "nursery" brooder houses for very young chicks.

Individual brooders have not, as a rule, been used on large plants, except as "nursery" brooders in which the chicks were put when taken from the incubators, and kept only for the few weeks when they were most dependent upon artificial heat maintained at a nearly uniform and relatively high temperature. On some large plants an entire building is used in this way as a nursery brooder house. More frequently one wing of a long brooder house is used as a " nursery" with individual brooders, while the other wing has pipe brooders, and into this the chicks are put as soon as they are able to stand lower temperatures and wider fluctuations of temperature. For some years this arrangement was very popular, and though it is still perhaps more common to find it than the exclusive pipe system, the latter as now generally put in with ample heating capacity and electric regulating attachment seems to give better satisfaction.

28. Individual Brooders in Small Houses.-For single pen brooder houses, and for houses of only a few pens, individual indoor brooders are very generally used. A common practice is to use an indoor brooder in a large coop or small house, from which the brooder can be removed when the chicks no longer need it. This arrange- 


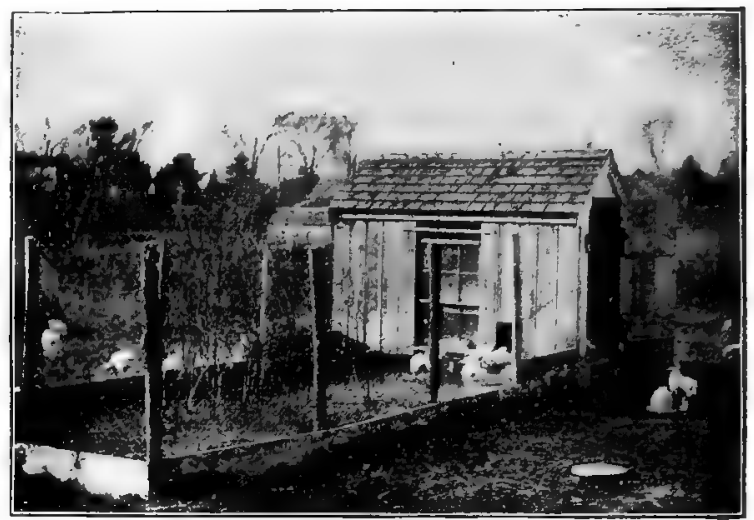

Brooder and Colony House.

ment is a favorite one with growers who hatch in the latter part of winter and early spring, as by that time the discomforts of caring for chicks in many separate houses are small as compared with what they are through early and midwinter, and the chicks need not be moved until marketed or put into winter quarters. While, when buying brooders to use in this way, the indoor style is preferred as costing less and suiting the conditions of a substantially built coop or house better, it is sometimes advisable when a brooder is to be used under cover in a space so large or airy that the surplus heat from the brooder would have little effect on the temperature of the place, to use an outdoor brooder, which provides a space intermediate in temperature between the hover space and the apartment in which the brooder is placed.

29. Outdoor Brooders. - It is only under exceptional conditions, such as mentioned at the close of the preceding 
paragraph, or because he has the brooders and wishes to make such use of them as he can, that the poultryman growing market poultry on a considerable scale uses outdoor brooders; but by many who grow a few chickens for market the outdoor brooder is preferred, and, in many instances is undoubtedly the most satisfactory and economical brooding arrangement. Thus one growing only a few roasters, hatching them early in the fall, and at that time requiring all his coops and buildings for other purposes, would be likely to conclude that outdoor brooders would just suit his circumstances, conditions generally being favorable to using them without inconvenience, discomfort, or special risk, while the chicks would be ready to go into other quarters by the time winter set in. For a few spring chicks; too, the outdoor brooder often comes in handier than any other arrangement, and I have known growers getting out a good many early chickens use outdoor brooders exclusively, though when the number required goes above fifteen or twenty the grower is apt to begin to find the care of them too burdensome, for it is generally conceded that the isolated and unprotected outdoor brooder is most likely to take fire, and therefore requires more careful attention than brooders in well built houses or coops.

30. Houses for Growing Stock.-We have to consider these in connection with roasters only, broilers almost invariably going to market right from the brooder. Several styles of these houses are shown in the accompanying cuts. The cut on page 52 shows a building on one of the large roaster farms into which chicks are put when first taken from the pipe brooder houses. Sometimes 


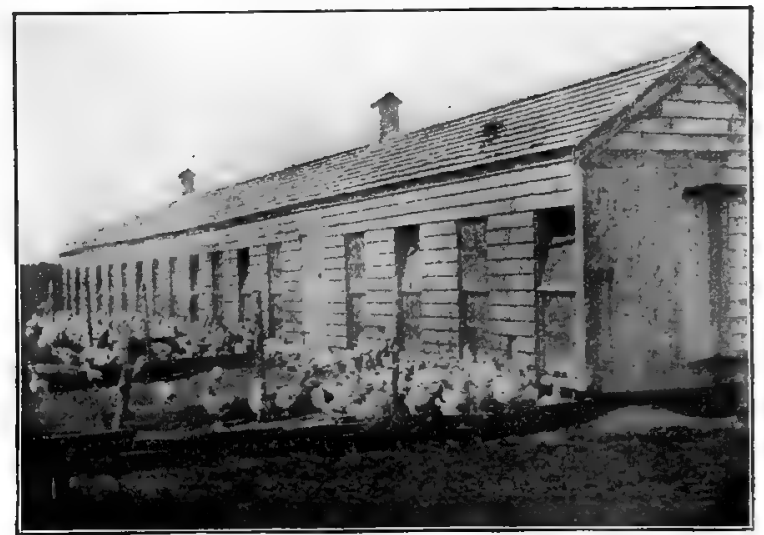

Long Brooder and Stock House.

when the accommodations of the pipe brooder house are insufficient, individual brooders are put in this house, and chicks removed to it several weeks before they are ready to do without artificial heat. The unevenness of results in hatching makes it quite necessary to have on any large plant some buildings which can be used for either small or weaned chicks, as desired, otherwise in a season of more than average good hatches the grower may easily find his very success in hatching a burden to him because of lack of suitable facilities for taking care of the chicks as they come.

For winter use, and until the chicks are well past danger from all the common ills of young poultry, houses in which several hundred can be kept are usually found more convenient. For spring and summer use, and for well grown chicks at any season, the South Shore growers use smalk colony houses of such styles as are shown on pages 50 and 
53. By those who had seen poultry kept only by the rules in general use, accounts of what was done with these smallcolony houses were long regarded with suspicion. A description of the way they are used, and explanation of some things about them not clear to those who have neither used or seen them in use, is more appropriate to the chapter on the general care of roasters, and will be found there. For the present it is sufficient to say that a number of these small houses, or of buildings of not much greater capacity, is to be regarded as a necessary part of the equipment of a plant where roasters are to be grown economically. The houses may vary much in design, according to the whim of the builder or the possibilities of the material to be used

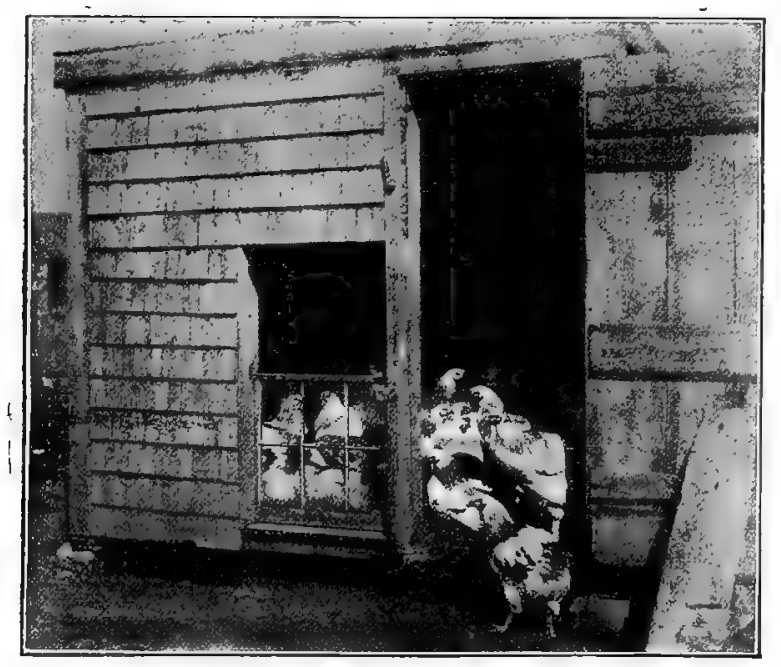

Colony House, $6 \times 8$ ft. Used for Fifty Roasting Chickens. 
I think the smallest I have seen were six by eight feet on the ground, and these were used for colonies of fifty chicks from nearly half grown to full grown in size.

31. Feed and Cook House. - Whether a special building is to be used for these purposes, is a question to be decided according to the circumstances in each case. Often it is more convenient to use a part of another building for a feed storage and cook room. One end of a brooder house may be appropriated for the purpose, or a room built over the incubator cellar or in connection with it. When supplies are bought as used, only a few days' or weeks' supply being kept on hand, large space is not required. On some quite large plants sheds having only a hundred to a hundred and fifty square feet of floor space are found amply large for cooking and for such supplies of stuffs to be cooked as are kept on hand, while other supplies are kept in any suitable and convenient place. As the reader will infer from such a statement, the successful plant of today is generally one that has grown slowly from small beginnings, and many of its appointments are of a makeshift character, a fact in no way counting against them, provided they answer their purpose as well as most of them do. On some of the plants of more pretentious beginnings, and on some of the long established farms that have had to replace their original buildings, commodious and well appointed buildings for storage, cooking, cutting hay, vegetables and bone, buildings in fact which provide for everything not included in the stock buildings are to be found, but the requirements for such buildings are so various that it would not be profitable to devote space to them in a small book of this class. Their dimensions, arrange- 
ment and equipment are according to the individual ideas and needs of the proprietor, and so one rarely finds the similarity in them that is found in buildings in which poultry is kept.

32. Poultry Killing and Packing Room.-Unless the product is to be sold alive there should be a small building or a room set apart to be used for killing, dressing, cooling and packing poultry for shipment. From the general practice in large poultry producing sections as well as from what I learn from market poultrymen in many places, I think that producers near the large markets generally find it more to their advantage to sell their poultry alive than to dress it themselves. That point, however, is one that each should decide for himself after having looked into it thoroughly, and of course, added the cost per pound to him of marketing his own poultry to the price he can obtain for it alive. In many places not having such division of labor in the handling of market poultry from the breeding stock to the table, and such careful grading of table poultry according to quality as is found in the localities adjacent to the best markets, it is undoubtedly better for the grower to dress his own poultry. In that case it is economy to have a special place for this work, and to have its few simple appointments conveniently arranged. As these will be referred to in the chapter devoted to marketing, nothing more specific need be said of them here.

33. Miscellaneous Appliances.-The really necessary small furnishings for the broiler or roaster plant are few in number, inexpensive; some of them can be made at home at almost nominal cost, and cheap articles that will answer the purpose are always procurable. If one wishes 
to economize in this direction he can make his own feeding troughs and boxes, and even convert articles usually thrown away into serviceable food or water vessels. Those who want articles specially made with reference to the uses for which they are designed, and in finish appropriate for a well appointed plant, will find them in great variety in the poultry supply stores. Of things really essential we might say that after the plain food and water vessels there are none, but one who wants all the "modern conveniences" will find them in the supply store or listed in its catalogue.

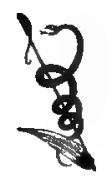




\section{CHAPTER V.}

\section{Hatching and Brooding.}

34. About Eggs for Hatching. - The grower of broilers generally begins operations about the time winter sets in. He may have from his own yards a part of the eggs he needs. If he is running many incubators he is likely to have to buy a large proportion of the eggs he wants at this season, and if he is wise he will be as particular as possible about where the eggs he buys come from. Once in a while a man will have very good hatches from eggs picked up at a store or commission house, but as a rule operators of incubators find hatches at this season none too good even after they have taken every precaution in their power to get good hatchable eggs. The most satisfactory way, when eggs have to be bought, is to make arrangements with poultry keepers in the vicinity who have laying at that time flocks of the general type of fowl from which it is desired to hatch, to take their eggs every few days. It is not always possible to get all the eggs one can use in this way, but one who continues in the business can within a few years work up a connection of this kind 
through which he is practically assured of all the eggs he can use. If local eggs to the number desired are not obtainable one must buy where he can. As the demand for eggs for winter chickens increases more and more, poultry keepers are preparing to supply it, and advertising eggs at this season, though the supply is and doubtless will long continue to be very limited in comparison with the offerings after midwinter. It is a good plan when buying eggs in large quantities for incubators to make sure that they are from desirable stock, and if the yards from which one proposes to secure eggs are at all accessible it is worth while to visit them for that purpose. A little time and a dollar or two, or even more, spent in this way, would prove to be wise expenditure, if it saved one from buying some thousands of eggs that might hatch well, but not chicks that would make satisfactory poultry.

35. Operating the Incubators.-As with every incubator sold goes a book of instructions as to the running of that particular make of machine, it would be superfluous to go into full details in a book of this kind, and I give as likely to be more useful to the reader a few general statements in regard to the management of incubators on plants where many are in operation. Some of the things I have to say may be found also in books of instructions, but my observation has been that many amateur operators are but little impressed by the general advices and cautions in lists of instructions, but having informed themselves on the few specific rules which they have to know in order to run the machine at all, pay no attention to the rest.

Perhaps the most common causes of failures with incubators are carelessness and neglect in attending to the 
machines, - not habitual carelessness and neglect, but occasional. Some manufacturers may be to some degree responsible for the general impression among those whohave not learned differently through experience, that an. incubator can go for twenty-four hours or more without attention. True, it may be left that long without anything going wrong, but the experienced operator learns to take no chances of that kind. Twice a day he goes through the routine work of caring for his machines, but he keeps. an eye on them at convenient intervals between times as well ; for some little thing may go wrong with a machineat any time, and the loss of an incubator full of eggs isquite an item.

After giving his machine or machines such regular attention as they require, and such incidental oversight as. is possible - within reason - the operator should study his machines. He should learn how they behave under different conditions, and how slight changes in moisture, ventilation, etc., affect them in operation, and also how variations, whether accidental or intentional, seem to affect the chicks in after life. The operator has to learn to operate machines, and each machine, under the particular condition to which his machines are subject, and in doing thishe is in effect learning the precise application of the general rules which the manufacturer has given for operating: his incubators - that is, he is cultivating judgment in applying his instructions.

It will greatly help a novice in incubation to draw right conclusions from his experiences in artificial incubation, if he can arrange to have one or twc hens incubating simultaneously with some of his machines and on some of the 
same eggs. This gives him more of an opportunity to check his work with the incubator. He can compare the air cells in the eggs in his incubator with those at the same stage of incubation under the hens, and so judge better about his ventilation and moisture. In case of failure or a very poor hatch with a machine results from the eggs under hens may indicate whether the trouble is in the eggs or in operation.

The ventilation of the cellar or other apartment in which incubators are run must be such that there will be comparatively little odor from the lamps. A bad smelling incubator room means impure air in the room, and that means a lack of pure air and oxygen in the egg chambers. Probably the best mode of ventilation is through waindows high up in the walls, having double sash, the outside one being hinged at the top, and the inside one from the bottom. The sash can then be opened as much or as little as is required. Their position with reference to each other sends the current of air entering the window upward and away from the machines, so that the cool air introduced is warmed before it reaches them. Another application of the same idea in rentilation is sometimes made in the doors which, as a rule, are double. A few large holes are bored near the top or bottom, it makes no difference which, of the outside door, and a corresponding number at the other extremity of the inside door, thus providing for a slow movement of air through these holes and the space between the doors. Slides can be arranged to close a part or all of the holes. With this provision in the door, and with one or more windows as described above, proper ventilation is a matter of judgment in the adjustment of the openings. 
There must be a circulation of air, but not so rapid as to. reduce the inside temperature so that the machines will be affected. A good rule to observe to secure this is to. ventilate as little as is necessary to keep down the odor.

36. Running the Brooders. - The commonest faults. in the construction and operation of pipe brooder houses. have been insufficient heating capacity and lack of air under the hovers. To the first of these causes responsibil-

- ity for the other may be assigned. Operators tried, and many still try, to get along with the smallest possible heater, and to economize heat by closely covering the space under the pipes. Many of the most successful growers today either use no covering on the pipes, or use it only for a few days when the chicks are very small. With heaters of greater capacity they can make the space under the pipes as warm as need be without shutting it up. closely. Thus the chicks are kept warm, and at the same time have abundance of air. The electric regulators in use are placed under the pipes and connect by wires with a damper in the heater, and also with an alarm bell within hearing of the operator at his house. Within a range of a few degrees the regulator controls the damper on the heater, opening or closing it as the temperature falls or rises. Should a variation beyond its power to control occur, it gives notice to the operator through the alarm. bell. It would be difficult to overestimate the practical value of this little mechanism to growers of broilers and roasters, relieving them of both work and worry in connection with the maintaining of the temperature of their brooders.

It is of the utmost importance that the chicks, during 
the first few days, be kept warm and not allowed to get far away from the heat. To insure these condition's it is customary to use at first a board, as described on page + , to confine them to the space under and near the pipes. For the first few days warmth is more essential to them than anything else but air, and the most approved practice is to keep the chicks quite closely in the brooder, and keep the temperature at $90^{\circ}$ to $95^{\circ}$, rather high than low. 'The action of the chickens toward the heat is sometimes cited as a reliable index of the proper conditions. While it probably is so to an experienced operator, a novice's lack of familiarity with the habits of chickens, and inexperience in observing them, is apt to lead him to make -serious errors in judging conditions this way, and it is generally safer for him to go by the thermometer for temperature. Under the system we are now considering, there is little danger of the chicks not getting enough air.

Another point to be noted in connection with this system is that there being a free circulation of air all about the chicks the chick capacity of the space is very much increased, especially for the very young chicks. Where the pipes are closed, and the temperature outside the hovers much below what is required, it is, of course, more difficult to maintain an even temperature under the hover, and it was this difficulty that led to so general use of individual " nursery" brooders for the smallest chicks.

In a general way the care of the individual brooder is much like the care of the incubator. By far the greater number in use are hot air brooders, heated by lamps or "stoves" which require attention as often as incubators. Not so high a temperature is to be maintained under the 
hover as in the egg chamber, but as the chicks require much more air than the eggs, the problem of ventilation is, if anything, more difficult, and it is the difficulty of supplying fresh air as required, without reducing too much the temperature under the hovers that makes it generally necessary in practice to reduce the number of chicks in the brooders so much below the manufacturers' rated capacity. After an approximately correct temperature, (about $95^{\circ}$ at the start, gradually reduced to between $80^{\circ}$ and $85^{\circ}$ by the time the chicks are three weeks old), the most important thing to observe is the purity of the air in the hover, and the operator should bear in mind that in securing this he must consider the chicks, as well as the lamp, as possible sources of noxious gases, and keep their number down to the safety point.

As the chicks grow, whether under pipes or in hot air brooders, there is less and less need of artificial heat, and the danger of chicks in close hovers becoming overheated through the combination of heat from their bodies, and from the lamp or stove, increases so much that the smaller the early losses in a batch of chicks, the greater the danger of things suddenly going wrong with chicks supposed to be well past the dangers of early chickhood. The surest preventive of troubles at this period is to avoid overcrowding. Whatever mode of brooding is used, brooder chicks require more care than those hatched and brooded naturally. The larger numbers kept together alter conditions, while the fact that the brooder, however good, cannot be to the chick all that the natural mother is, makes it more necessary that the keeper should exercise close watchfulness and see that everything is right and kept right. To give 
one or two illustrations : A brood of a dozen chicks running with a hen may have their drinking water in an open saucer, and paddle through it, wetting themselves a little, but fifty or-a hundred chicks with access to an open water vessel will soon have themselves and their surroundings in sorry condition, and so many bedraggled brooder chicks will hardly dry off without some of their number being the worse for the wetting, while it is no uncommon thing in such a case for chicks (and even ducks) to be so exhausted in the dabbling that they are run over and killed by the rest.

In feeding, too, there must be more care. The average hen hatched and brooded chick will thrive in spite of irregularities in feeding which would stunt and perhaps eventually kill the average brooder chick. When all goes right by the artificial methods, results should be identical with the best results by natural methods, but the operator of incubators and brooders who keeps things right so generally that his average results are as good or better than average results by the other method, does it by combining good judgment with unfailing vigilance. 


\section{CHAPTER VI.}

\section{Feeding Systems - Foods and Feeding.}

37. The Two Feeding Systems.-According to their preference in methods of feeding, poultry keepers today may be roughly divided into two classes - one comprising the advocates of $d r y$ feeding, the other the advocates of wet feeding. The line of division between these classes is not as sharply defined in practice as would appear from the statements of exponents of the different methods. It seems to me that the attitude of representatives of the two schools toward practical feeding, and toward each other, is best expressed by stating that they differ more in their philosophy of feeding than otherwise. The advocate of wet feeding regards a judicious alternation of wet or soft food and hard grain as generally productive of best results. The advocate of dry feeding considers the use of wet foods dangerous, or at least involving greaterrisks than the use of all dry rations of grain, with what "wetting" is required supplied in pure water and succulent green food. 
Anything like an extended or exhaustive discussion of the numerous points which must be covered-in a comprehensive treatment of the question is impossible in the limited space allotted to the subject in this book; but it is in order to observe that whatever the first preference of a poultryman, as based on theory or report of results, may be, he must ultimately come to the method which is most in harmony with his conditions, and with the other parts of his system of poultry keeping. So it is well for him not to feel too much faith in any one system or method, for there is none that will insure good results under any and all conditions, and in feeding, as in other things, one must learn to adapt his methods to his circumstances, changing them or not, as conditions and results seem to require.

38. Mash Systems of Feeding. - Under this head-ing I would include all methods in which wetted, scalded, steamed, or baked ground feed stuffs, or mixtures of the same, are used as the whole or a part of the ration.

A ration of all wet, raw, or partly cooked foods, or of cooked foods soaked before being fed, should never be used in connection with artificial brooding. Such a ration is an unsafe one, except for chicks roaming with hens on a range where seeds of various kinds are abundant. In other words, it is safe to feed an all wet diet only when what is given the chicks forms only a part of their ration, and what they secure by foraging counteracts the bad tendencies of too much wet food. The risks of an all wet ration are greater when chicks are brooded artificially, because bad effects of errors of temperature have the same tendency as an excess of wet food-i. c., to cause bowel 
trouble-hence the two things together make a double risk. I do not mean by this that it is not possible to have chicks thrive on such a ration. Good broilers have been grown that way; but the risks are greater than when a safer method of feeding is used.

A ration of all cooked food may be used for broilers with good results, and is often used for young chicks up to broiler size, though they are to be kept for roasters or for stock purposes, but it is questionable whether such a method, used exclusively for the first few months, is advisable for chicks that are not to be marketed as broilers. The usual effect of an all soft grain food ration, with some green stuff, meat, and grit, of course, provided, is to make a temporary rapid growth, while the digestive organs used for soft foods only, and so not developed in proportion to the general development, become inadequate to the work required of them later in life, when economy imperatively requires the use of a nearly all hard grain ration. For a few months chicks may be fed exclusively on a steam cooked mash, or baked cake, and some growers have thought that method preferable.

The more common method has been to alternate soft and hard feeds, or if not feeding them in regular alternation to make about half the day's ration soft and the rest hard. Thus one very successful grower used to start his chicks on stale bread crumbs fed alternately moistened with milk and dry, practically a balancing of tendencies toward looseness and costiveness. Others have used baked cakes or steamed mash or scalded mash. The baked "johnnycake," whether of corn meal alone or of a mixture of mill stuffs and the various kinds of mashes, are safe or unsafe foods 
as a steady diet according to their consisteney. Their composition has more effect on growth than on health. A cake that is heavy and doughy, or a soggy mash, will quickly put a good proportion of the chicks in brooders to which it is fed to the bad, while a food of like composition but well prepared would give very good results. Variety in a ration generally gives better growth than a monotonous ration. especially if the ration contains but a single article, yet it is possible to get better results from a well made all corn meal cake than from a poorly made ration much better balanced in its constituents. Such facts as these will account for some of the differences in method, and radical differences of opinion as to values of methods which puzzle the beginner when he discovers how even successful poultrymen will disagree in matters of this kind.

Baking cakes is too much work to allow of the use of much baked cake where large numbers of chicks are handled. For a few chicks it may be the most satisfactory way, particularly when the chicks are small and require but a little food at a time. Under such conditions a baked cake comes in very handy, as it will keep for days -when a mash would get heavy or sour or moldy. Some large growers like to use baked cakes for their youngest chickens, but for economy of labor it is better to have one system for all chicks, and so when food is prepared make one job of it.

If a cake is used it may be either of all corn meal or of corn meal mixed with other articles. Here are some receipts that have been given for cakes :

Add a little soda to sour milk; stir in corn meal or corn chop to make a stiff batter- the stiffer the better. A few 
infertile eggs added improve the cake. Table scraps may be mixed in the batter.

Grind together corn, wheat and oats, equal parts; mix with milk, and bake.

Grind together $20 \mathrm{lbs}$. corn, $20 \mathrm{lbs}$. oats, Io lbs. barley, add ro lbs. wheat bran. This makes what is known as "excelsior meal." To make cake of this : Take one quart sour milk or buttermilk, add a little salt and molasses, a quart of water, a heaping teaspoonful saleratus, thicken with the meal a little thicker than batter for corn cakes; bake in shallow pans.

Take I pint corn meal, I teacup bran, I teaspoon meat meal, I raw egg, I teaspoon soda, I teacup cold water; bake two hours.

Take 3 qts. corn meal, I qt. wheat middlings, I cup meat meal ; mix with water or skim milk to which has been added 4 tablespoons vinegar, 2 teaspoons soda.

\section{To make a good mash:}

Make a stiff thick mush of corn meal stirred into boiling water. Into this stir the other ingredients used.

A very satisfactory mash is made by adding bran alone to the mush, the proportion of this mash should be about half and half corn meal and bran, and when finished should be light and crumbly, but not mealy - that is, a spoonful or handful of it should have a tendency to crumble like a Iump of earth, the particles of which without being wet 
enough or firm enough to retain their form, still stick together somewhat, crumble - but do not separate as the particles of dry earth, ashes, sand, or meal do. It is hard to give in words an idea of the consistency of a mash. Describing consistency is much like describing a color or a sound.

There is this much to be said about the mash though : If one does not get good results from mash feeding it is because his mash is inappropriate - in some way faulty, and if after several changes he still fails to make a mash that gives him good results, I would certainly advise him to try another method, for there is no one method better than others for all people under all circumstances, but the best method for each is the method that gives him best results.

For a mash with more variety in it than that given above, take corn meal and ground oats, equal parts, scald or cook in a mash, then stir in as much bran as it will take, and add five to ten per cent of meat scrap or meat meal. For small chicks' it is better to go not much over five per. cent of meat, but as they approach market age the quantity may be increased.

If mostly mash is fed make the mash as dry as it can be mixed, and feed it either warm as first mixed or before it becomes cold. As a rule it is not advisable to feed a cold mash to small chicks in cold weather, for it is apt to be heavy and have a tendency to cause indigestion. Aim to mix up no more mash at one time than can be used before it becomes cold. (Cover up and set in a warm place, it will keep warm and nice for a day); but if a mash does 
become cold and soggy warm it up, and either mix with some fresh mash or add dry bran and meảl to improve its consistency.

It is not possible to give comprehensive directions about mash making and mending. All that can be done in that way is by suggestion-giving the reader an idea of what is possible. He must work it out for himself, just as he works out problems of incubation and brooding, learning by experience how to balance the ingredients to get a composition that the chicks will eat with relish and thrive upon.

39. The Dry Feed System.-Leaving out of corrsideration, for the time, the question of relative possibilities of the two systems, I think it may be positively. affrmed that far the greater number of persons growing: chicks in brooders, who have tried the two systems, find! that they get better results by dry feeding — that is, they find that system easier to apply. It is a simpler system. Possibly the best results in individual growth or production, when dry feeding is practiced, are not, taking one case with another, as good as the best results by a system that includes the use of some soft and moist grain feeds. My personal opinion is that they are not, but the question is one not easily demonstrated conclusively, and therefore better considered an open question. But it seems quite plain that in the majority of cases losses of chicks have been much smaller by the dry feed method. As every lost chick has to be paid for out of the price received for those grown to marketable age before one begins to figure net proceeds, it is clear that the system giving the least losses will, in many cases, be the more satisfactory system, and 
the one that, in a majority of cases, will give the greater profit, though it may not give the best obtainable quality in individuals.

Is dry feeding, then, to be recommended as the best system for all beginners? Not at all. A good proportion - though not the majority - of beginners will get as good or better results from the start by other methods. The best way for the beginner is to adopt the method he thinks he would prefer, or that most convenient to use, and follow it until he has a good reason for modifying or changing it. No one can tell in advance which system will suit him best, and while the dry feed method is generally safer for novices because it operates as a check on some of the other errors they are most likely to fall into, in case they escape these other errors the features of the dry feed system which made it good under other circumstances may be the very ones that will make it unsuitable for them. The feeding system must fit the other parts of one's poultry keeping, and a poultry keeper would be very foolish who would try to make his methods conform to any well defined system after it became apparent to him that in his case modification of either system, or a combination of the two, would work to better advantage. We must not lose sight of the ract that our division of feeding methods into two general systems is an arbitrary distinction which has no practical use beyond what can be done by thus dividing the subject when discussing it to make the whole question of feeding clearer to the beginners who too generally assume that there is one best method, and all others are either bad or inferior to it.

40. What Is Dry Feeding? - There are various methods of diy feeding, just as there are various methods 
of feeding rations composed in whole or part of mashes or cakes. The grains may be fed all whole or cracked, or a part ground and mixed together, making what is sometimes called a "dry mash." The feeding may be in hoppers or troughs with food before the chicks for the picking all the time, or a part of it may be scattered in litter to induce them to take exercise. Leaving food by small chicks is not very generally practiced, for so many being confined in a small space, and they being so small, food that is casily accessible to them is very likely to get fouled with their droppings and with their running over it, and in that condition much of it is wasted, or, if eaten, becomes a menace to health. On this account the rule of "little and often" is almost universally used for small chickens, no matter what the food used. When the chicks become large enough to eat out of troughs or hoppers so constructed that they cannot foul the food in them, many growers of both broilers and roasters keep food before them all the time.

Probably four-fifths of all the dry fed chickens are not fed ground grains in a dry mash. Most growers using the dry feed system either buy the prepared mixtures of small and cracked or broken grains for chicks or make their own mixtures. The commercial mixtures as a rule contain a much greater variety of grains and seeds than the home made. Some of them also contain grit much in excess of what is required, and low priced grains in larger proportion than they should be for the price asked. Hence while it is often assumed that the prepared food is a boon to the poultryman who is not a judge of foods, the fact is that he needs to use the same judgment in buying prepared mixtures that he does in buying straight grain products of vari- 
ous kinds. Admitting that the proprietor of the mixture with his expert judgment will often do better for the novice than he is likely to do for himself, it is still true that the novice pays for every service of this kind, and the sooner he is able to dispense with such services the more economically he will grow his poultry.

The strong point in favor of these preparations is not that they are cheaper, or better than poultry keepers can make for themselves, but that they omit nothing that is necessary, and provide for a constant variety. Too many poultry keepers of some experience, as well as novices, fail to provide all the things their chicks and fowls need - so that they can have them as they need them. The manufacturers of prepared mixtures of various kinds take account of this in the preparation of their goods, and so give the poultrymen an article which makes good some common shortcomings. This explains why so many people are more successful with prepared foods.

There is one misapprehension about the use of prepared foods that, in the interests of economy, ought to be removed from any mind that harbors it: The impression is very general that prepared foods are used exclusively by many large growers of broilers and roasters. This is not the case. There are many small growers using prepared foods exclusively, but the large growers, and in fact most of those who figure expenses closely use the prepared mixtures to start the chicks, and as they grow older change to part cheaper grain, generally fine cracked corn, the proportion of corn being gradually increased until in the case of chicks reserved for roasters they are on an almost exclusive corn (for grain) diet when three or four months old. 
Now the question comes up in the mind of the reader:Which of the mixed foods are good? One is generally safe in buying a mixture sold by a reliable supply house. The best of them sometimes make mistakes, but a house that has a reputation to maintain will make its mistakes. right, and the quality of its goods will be on the whole very uniform. There are a number of exclusively advertised and well known brands of chick feed and scratching feed that a poultryman can buy with the same confidence with which he buys a reliable brand of flour. Whether that particular brand will suit him as well as another can only be ascertained by trial, but he can rely on its containing nothing in itself harmful. The same with the mixtures. frequently made and sold locally. A reputable house tries to. serve its trade well. If it makes mistakes, they are honest. mistakes, which it corrects as soon as they are pointed out.

Where then is the need of judgment on the part of the buyer? Right here: Suppose he gets a hold of a lot of food of a well known brand not up to quality for that brand, lacking, we will say, in some one of the important items in the mixture. Trusting implicitly in the reputation of the goods, he may not notice what is lacking in thislot until he has occasion to look for a reason for his chicks. not doing as well as usual. It takes time then to correct the trouble, and the loss through check in development isone that cannot be made up. I emphasize such points as. this because it cannot be too strongly impressed on the beginner in poultry culture, that no merit in breed, feed, or method is so sure and unchangeable that he can rely absolutely upon it. On the contrary experience with good fowls, foods, and methods should educate and train a poultryman's judgment and make him self-reliant, and he misses 
one of the advantages of buying good feeds if he fails to learn from them to judge food stuffs.

The ground mixtures for chicks cannot be as freely recommended as the mixtures of cracked and broken articles. In general they contain too large a proportion of indigestible or innutritious waste which cannot be separated from the other elements, and is very likely to cause the chicks to eat the food less freely than is desirable, or if eaten cause digestive and bowel troubles. Ground mixtures are to be bought only after careful inspection, and used always with caution whether fed wet or dry.

41. The Feeding Systems in Practice. - Young chickens require no food for from twenty-four to thirty-six hours after hatching. They can go longer without it, but in general they are ready to eat a little bit after the first day. At first they eat only in very small quantities. Indeed in feeding a brood of chicks with a hen one can hardly notice that the hen and chicks are taking any more than the hen would until they are several weeks old. After that the quantity eaten by a chick increases very rapidly. Most people feed far too much at a time to their small chicks, with the result that much food is soiled and wasted.

When brooder chicks are fed in pans or troughs, and feed kept before them most of the time, they may not take as much exercise as is needed to keep them out of mischief and in good condition. A lot of chicks with nothing to do often develop some troublesome vice, like cannibalism, or standing idly around; there being no inducement to take exercise, their blood circulates sluggishly, they feel cold, and the attendant observer observes the phenomenon, often considered as something of a mystery, of chicks huddling together and to the heat when the thermometer indicates a 
temperature at which they ought to be comfortable, well spread out under the pipes. A little litter on the floor and a handful or two of grain in this for the chicks to work for will often make a surprising change in their behavior toward the heat. This scratching grain should be given even when most of the food is fed in troughs or hoppers. The chicks will often leave the grain that is easy to get and scratch busily for what can only be obtained by working for it. It is the chick nature to do that way. Compulsory scratching is not needed for small chicks unless they have become so sluggish that they will take no exercise until forced to do so, but the opportunity to scratch should always be given brooder chicks until they are to be fattened. With abundance of food to be had without scratching they will exercise just about enough to keep them in condition. Many a time $I$ have seen a brooder full of chicks cured of a mysterious indisposition by simply giving them opportunity and slight inducement to take exercise.

It is especially necessary to look out for this when the chicks are confined constantly or for long periods indoors. When they get out the change from inner to outer air stimulates them, the sun is a tonic, and there is variety enough in their little lives to keep them in motion, but in the house on dull days they want something special to do.

When chicks go "off their feed" and eat mincingly, though there seems nothing in particular wrong, it is apt to be because they are overfed, and nothing will bring them out of this quicker than to let them go without feed until they are ready to eat with appetite. If they have been fed every two hours or so, skipping a single meal often gives their digestive apparatus a chance to adjust itself for a fresh start. If food is kept before them constantly, and they do 
not seem to eat right, remove it for a few hours and they. will be ready to eat a good ration when it is returned to them, and thus get back into regular habits.

How Often and How Much to Feed:

The small chick, as has been said, takes its food in almost infinitesimal quantities at first, but it wants its meals often. If only what the chicks clean up within a few minutes is given them at each feeding they will eat about once in two hours. As they take food in larger quantities it will be found that two hour intervals between feeds are too short, if the chicks are given all they will eat at each meal. Some keep the chicks in good appetite by continuing feeding at two hour intervals, but never feeding the chicks all they want; others give the chicks what they will eat, and lengthen the intervals between feeds as much as necessary to keep the appetite hearty. The latter way I think the better one. It reduces labor, and it is more natural. With broilers one will not get much beyond three hour periods between meals, but with roasters he can soon get on a three-meals-a-day basis.

For quantity no definite rule can be given. It is desirable to have the chicks eat all they can digest, and that will vary with their digestive capacity as well as with the composition and quality of the food. The feeder should aim to have a diet that will be eaten freely and digested without inconvenience. With such a ration, with the necessary exercise and other accessories, there is little danger of overfeeding, and he may be liberal to the point where waste of food begins.

In a mixture of grains the chicks get variety in every meal. When for the sake of economy it is desired to feed as much as is desirable of a cheap grain, it may either be 
made the larger part of a mixture, or may be fed separately several times a day, the other feeds, given alternately with it, furnishing greater variety. Cracked corn is a favorite food with nearly all growers of market poultry for this reason, and is mostly used in larger quantities than any other one ingredient in both wet and dry feeding. At the prices that usually obtain comparatively little wheat or other grains is used by large growers. Those who use mashes alternate them with cracked corn. Those who feed dry alternate cracked corn with a more expensive mixture until the chicks are several weeks old, and considered past "the danger period." After that the larger growers nearly all get down as near as possible to a diet of corn, meat scraps and some green stuff, no more of other ground or whole grains being used than is necessary to mix with corn meal in cake or mash or to relieve the monotony of an all corn grain ration. The soft roaster growers feed practically nothing but cracked corn, meat scrap, and green food to their chickens after taking them from the brooder houses and placing them in lots of fifty in such houses as that illustrated on page 53, or in corresponding larger lots in the slightly larger colony houses sometimes used.

42. Green Food.-Neither green food nor meat is absolutely essential in the diet of young chicks. They have often been known to grow and thrive for weeks without either. But growth is generally better, the chicks healthier, and the risks in handling them less when green food and meat food are supplied practically from the first. For green food there is nothing better than cabbage, which can be fed by putting a head, leaves, stump and all in the pen and letting the chicks pick it to pieces. There is no 
need of cutting it up for them. They can do it for themselves, and get good exercise while doing it. They will clean up all but the toughest fibres of the stump and root. After cabbage there are other foods which are sometimes grown in boxes or frames for winter chickens. Lettuce, wheat, oats, are all used; but such things can hardly be produced profitably for large numbers of chicks, and the careful grower of winter chickens will make due effort to have an ample supply of cabbage. On land where roasters are grown cabbage can be set out after the bulk of the crop of chickens is marketed in June or July, and in an ordinary season will have ample time to make a good crop of inexpensive green food for the next crop of chickens.

A favorite crop with growers of both broilers and roasters is winter rye. When there is little snow during the winter the chickens can get what green food they need on the patches of rye in the yards or near the houses, while whatever the winter, the rye furnishes green food for the growing roasters in spring long before grass or other green crops are available. When dry feeding is the method employed it is more important that the chicks get some succulent food, and if such green foods as have been mentioned are not available root vegetables may be fed raw.

43. Feeding Meat.-In feeding meat to chicks being reared artificially one must be more careful than with chicks at liberty with hens. Under natural conditions chicks often stand foods which soon show bad effects when fed under artificial conditions. Meat meal of poor quality, really not fit for anything but fertilizer, may be fed in moderate quantities to grown fowls and to chicks with hens without bad effects, but the grower using artificial methods 
finds it not safe to use meat meals or scraps except such as are of good quality, sound and sweet. A great deal of trouble with brooder chicks is due to poor quality meat, which the user does not suspect because he observes no bad results from feeding it to other stock. Of green cut bone, cut very fine, all the chicks will eat may be fed if they get it every few days. The cut bone should not be sour or heating.

In dry feeding the meat meal or scrap used is fed separately, kept before the chicks all the time. In wet feeding the prepared meat foods are generally mixed with the cake or mash in proportion of about five to ten per cent of the bulk of its ingredients when dry. The proportion should be governed in part by the quantity of mash fed during the day. If the mash is fed only once a day ten per cent, or even more, of most brands of prepared meat is not too much. If two or three mashes are fed a day the amount may either be distributed through them or fed all at one time, the other mashes containing no meat. For rapid forcing the amount of meat scrap may be very much increased, but until one has had experience enough in handling chickens to recognize bad effects of overfeeding meat as soon as they appear he had best use small portions of nieat in the mash and give a part of the meat separately. To be sure he might feed all meat separate, and none in the mash, but it is nearly always found that a mash with some meat in it is eaten with greater relish. As to the limit of the amount of meat that can be given, I have known growers use as much as one-fifth meat in a mash fed several times a day. I would not advise a novice to use so much, except perhaps for a short period before killing. 
44. Drink.-Water, fresh as often as is necessary to have it reasonably clean, is as necessary as good food. When we speak of cleanliness in matters concerning poultry we always mean relatively clean. Perfect cleanliness is practically out of the question in the poultry yard. The poultry keeper must learn to draw the distinction between things that have some dirt on them and things that are dirty. Within limits he can tolerate the former, the latter he should not have about his premises. A little of the dust from the floor on the water, even a little excrement in it does not constitute a serious risk, but drinking vessels allowed to get slimy and nasty are a common cause of trouble. Clean them as often as necessary to have the vessel clean, (a good rinsing once a day should be enough) but don't think it necessary to empty a vessel and put in fresh water if a tiny bit of the droppings falls in it. That is. the kind of work that takes up so much of the time of some poultrymen that they do not find time to do other more necessary things.

Milk is good for chicks, whether given as a drink or used to mix the mash. Slightly scalded milk is good to correct a simple diarrhea. In giving it to brooder chicks as a drink it is better to use a drinking fountain, even if fountains are not used for water, for dabbling in milk the chickens smear each other up and make a bad mess. Whether milk is given or not the chicks will want water, and should have it.

45. Grit.-Growers of chicks using artificial methods generally consider it of greatest importance to keep the chicks constantly and liberally supplied with grit. Many of them give grit before they give any food, claiming that 
it is necessary. In this they are probably wrong, for it is certain that many lots of chicks have got along very well without grit, and I have had reports on a good many cases where there was good reason to suspect that chicks kept too long without food, but given grit freely, swallowed much more grit than was good for them with the result that the digestive apparatus became deranged at the start. Chicks need some grit, but not more than they will take freely when well fed. If prepared chick foods are used for- even half the ration there will not often be need of supplying more grit than these contain. There is probably none of them in which the proportion of grit is too small, and many contain several times more than is necessary. When chicks are fed wholly on preparations containing no grit they should always have access to a supply of it. Their need of it seems to depend on the food given them, and to vary much in different chicks.

46. Charcoal. - The charcoal question is very like the grit question. Many growers keep it before the chicks. Some chicks thrive without it. Its properties being such that it aids digestion and purifies the blood, it is clear that the need of it will exist, and the beneficial effects be apparent in case of chicks that have weak digestion or indigestion, or poor circulation, as it would not in chicks that were in good condition. Considering the number of successful growers who use no charcoal, it cannot be said that there is as much need of keeping it always before chicks, but if chicks are not thrifty it is one of the simple things to supply before changing foods or beginning to give medicines. 


\section{CHAPTER VII.}

\section{Some General Points on Roasters.}

\section{Peculiarities of "South Shore" Methods.-} As the broiler goes direct from the brooder to market the broiler growers' problems in management do not go beyond the methods of handling chickens in brooder houses. The grower of large roasters has to consider how best to carry his crop-some of which was dereloped enough to be sold for broilers early in the winter - to the season of high prices in the following summer. He saves in feed by using the lowest priced grain (corn), and in cost of feeding by keeping food standing before the chickens all the time. The usual way to feed these chickens is to have in each house a trough or hopper of cracked corn, another of beef scrap, and a pail of water. While the supply of cabbage lasts, cabbage is given frequently: after that the only green food the chicks get is the rye they pick for themselves when the snow is off the ground. As snow rarely lies long in that locality, they are seldom long without green food. 
To most poultry keepers the incomprehensible thing about the methods used here is that crowding the weaned chicks so densely in small houses does not result in losses such as under ordinary circumstances attend crowding that does not seem to be anything like as bad as that practiced here. The reason is found in a very radical difference in the way the houses are used. The ordinary way is to shut up the houses. The method in use here is to let in plenty of air. The house is never shut close. Either window or door is always open, and oftener both are open. With plenty of air the chickens, though crowded for room, get along quite comfortably, even when a storm keeps them in the house for several days. The system of feeding makes the droppings quite dry, and, as a rule, the difficulty of handling crowded fowls that have loose droppings does not have to be considered. The chickens can stay in the houses for a few days, or a week may pass without the droppings being removed. Of course cleaning up with the chickens in the house is out of the question.

When warmer weather comes the chickens still remain in the houses at night and as much as they wish through the day, but are practically free to go where they please. They never go far. The growers here believe in placing no restraints on them outdoors, and depend on the supply of food in the house to keep them from roaming far. They say that the well fed chicken will not want to go far, while the chicken that is not confined is contented, and so keeps in better condition at less cost.

Their system is perhaps not in every respect ideal. It has defects which need not be dwelt upon here. But notwithstanding these defects, the fact remains that these 
growers are producing far the best poultry that goes to the American market in quantity, and that they are, as a class, making more on their investment and labor than any other class of poultry keepers in this country. That being the case, it would be superfluous to discuss improving their system here. When the reader has paralleled their success by their methods - which are the methods which, to date, have given the best all round results - he will be ready to consider how to improve them - if they then seem to him to need improving.

An important feature of the system used here is the thorough cleaning up of the houses and yards once a year. As there is a period of two or three months between the marketing of the last of one crop and the setting of the first incubator for the next, and at this time there is not a chicken or fowl in the houses used for growing stock, it is possible to give the houses and land adjoining them a more thorough cleaning up than the ordinary plant ever gets. The earth floors of the houses are removed and new earth or sand hauled in. The fences, wire netting on stakes, are taken up and the land plowed and planted to some crop for next winter's chickens - generally to winter rye.

48. Caponizing. - The cockerels of the winter chickens grown for roasters are caponized, but are not dressed like or sold as capons. Cockerels and pullets alike go to the market as large roasting chickens. The operation of caponizing need not be described here. The reader who wants to learn caponizing should learn from an expert operator if possible, or failing that should use the full instructions which special books on caponizing give.

Chickens grown for summer roasters and marketed at 
four or five pounds weight need not be caponized. As market demands are now there is little advantage in caponizing except for cockerels that must be held beyond the age at which their meat begins to harden.

49. Spring Hatched Roasters. - The small and medium sized roasters marketed in summer and early fall. are mostly cockerels from the spring hatches of poultrymen: producing chickens for laying or stock purposes, but a proportion of those coming from nearby points to the large: markets is stock of both sexes either produced expressly for roasters or started for broilers, and for some reason carried over. The spring hatched roasters can be handled just the same as the winter chickens after weaning, but they are not caponized unless they are to be grown to full size and sold the following winter, and little of that is done except in a few localities where caponizing is quite general among the farmers. The capons produced in this way are much superior to old cocks and staggy cockerels, but do. not compare with the South Shore chickens or with the best small and medium roasters from uncaponized stock as. marketed in the summer. The grower who sells cockerels as roasters must, however, look sharp in disposing of them. and let as few as possible stay in his yards long enough to. become "staggy." It is always advisable to work them off a little small but soft, rather than have the weight gained hard meat. 


\section{CHAPTER VIII.}

\section{Fattening.}

50. Fattening Broilers. - A fat broiler is quite a rarity. The best that can be done, in general, is to have them plump. From what $I$ have seen of broilers in the markets and on exhibition I think that a grower will be more successful in getting plump specimens by selecting and breeding for that quality than by trying to fatten slim specimens of five or six weeks old chicks. However, for chicks that are not plump something must be done. The usual way is to feed a mash of about two-thirds corn meal and one-third bran. To this some breeders add molasses and cotton seed meal, some ten per cent cotton seed meal and twenty-five to thirty per cent beef scraps. Such heavy feeding of rich foods is accompanied by a good deal of risk, and it is no uncommon thing for a grower to hurt his chicks more than he helps them by it.

The natural tendency of the chick is to turn all nutriment to growth and development, and it may do this with a "fattening" ration-- until the digestive system goes to pieces as the result of high feeding. The fattening of 
broilers is, therefore, an operation to be conducted by the novice with great care. It is better for him to be satisfied at first with marketing them in just good condition than to make losses by attempts to use extreme fattening methods. As he grows in experience he can gradually approach these methods, going as far with them as he finds safe for him.

51. Fattening Roasters.-As a chicken matures and requires less and less food for growing bone, muscle, and feathers, the food consumed in excess of these requirements goes to reproduction or to fat, according to constitutional tendencies and to conditions. The growers of soft roasters have a considerable proportion of their pullets begin to lay some weeks or even months before it is desired to sell them, and all such are sold immediately, because after laying begins the meat.becomes hárder and dryer - more like that of an old hen. Other pullets will keep right on growing and not fatten until well on in the season. A proportion of the caponized cockerels also develop into slips, and the meat becomes hard and unfit for the trade for which it was designed. The bulk of the crop, however, is generally carried to early summer in good flesh. Then if more fattening is needed it is accomplished on the same feeding that has been used for the chickens since weaning, by merely confining them more closely so that they may keep quiet and let the fat accumulate. About ten days confineu ent - in pen and small yard - will usually make healthy chickens in good condition as fat as is desirable. For years I have fattened cockerels for frys and roasters on either the same ration the growing stock was getting, or this ration changed merely by using more meal in the mash, and all 
cracked corn for grain. Cockerels so treated before sexnal characters are strongly developed will, if they have grown steadily and well from the start, make as fine and tender meat as can be produced, and cockerels of slow maturing stocks will be soft meated until quite full grown.

52. Difficulty of Fattening in Hot Weather. - In very warm weather it is sometimes impossible to fatten chickens by ordinary feeding methods because the chickens either will not eat a heavy ration freely, or are almost immediately upset by it. It is in such emergencies that the grower is led to consider special fattening by the use of the cramming machine. These occasions have been so scattering and so rare that no extended interest in special fattening methods has yet developed among growers of the best grades of market poultry, and I consider it altogether improbable that European methods of fattening will obtain in this country within our generation; except to improve poultry not properly grown by the growers. 


\section{CHAPTER IX.}

\section{Selling and Preparing for Sale.}

53. Selling Alive and Dressed. - The question of selling alive or dressed was briefly mentioned on page $55^{\circ}$ As there stated, the decision as to which is the better way to sell must be made by each grower for himself. The grower located where there are many persons producing poultry, and collectors making regular trips buying poultry, will generally, if - as we must suppose - the practice of most thrifty growers indicates what is best to be done, find it more satisfactory to sell both broilers and roasters alive. But many are so situated that they cannot sell alive to so good advantage, while all who sell to retail or private family trade must sell dressed. If one does not know how to dress poultry it is better to hire an expert picker at so much per chick or fowl. Many small growers about Boston have the marketmen to whom they sell send thenr a picker whenever they have enough chickens ready to dress to keep a man busy for a day or more. A grower retailing his fowls should learn to dress them himself. 
For such the instructions which follow are a help; but to really learn how to do such work well and expeditiously most people need personal instruction, and for one who thas to do it in his business, it is worth while to go and work for a week or two in an establishment where poultry is dressed by the thousands.

54. Methods of Picking.- There are two methods of picking fowls - dry picking, in which the feathers are removed dry, after the bird has been bled and stunned, while the fowl is dying; and scalding, in which, after life is extinct, the bird is immersed in scalding, not boiling, water just enough to steam and loosen the feathers, which are then much more easily removed than by dry picking. A properly scalded fowl when picked presents as attractive a carcass as a dry picked one, but while it is easier to remove the feathers when the scalding is done right, so much of the scalding is done wrong that in the markets where choice poultry brings best prices, scalding is in disrepute, and the best of scalded poultry usually sells a few cents, two or three, below dry picked poultry of the same quality at wholesale. I am inclined to doubt that the retailers give the difference to their customers. The grower dressing stock for eastern markets should dry pick it. Unless a grower is expert in scalding he will find it to his advantage to dry pick for any market, for there is much less danger of his making his poultry look bad.

55. Methods of Killing.-Fowls that are to be scalded and sold with head off may be killed by cutting off the head with a hatchet - the common way through the larger part of the country. If to be sold, as in most large markets, with head on, they must be killed by bleeding, 
sticking either in the mouth or neck. The former method gives the best looking carcass, as there is no outward disfiguring wound, but as bleeding in the mouth, unless skillfully done, may not allow the fowl to bleed thoroughly, an inexperienced killer will find it better to stick in the neck when dressing for sale - at least until by practice on birds. to be consumed at home, he learns to kill by sticking in the mouth. For this purpose special killing knives for poultry are made, which may be obtained of any supply. house.

In general, a New England killer works sitting down with a coop of live chickens at his left, a box for feathers at his right, and a pail to catch the blood between his feet. Taking the chicken under his left arm, with the head in his left hand, while the body is held fast between his arm and side, he holds the mouth open with the thumb and fore finger of the left hand, while with the knife held in the right, he makes a deep cut across the mouth to penetrate the brain, then turning the knife makes a long cut toward the point of the bill, to allow free bleeding. Next with a short club he stuns the bird by striking on the back of the head, then begins to remove the feathers. In some establishments where many pickers were working on large fowls, I have seen pickers go to the coop, get their fowl, stand while killing and stunning it, then sit down to pick.

The "New Jersey" method is to hang the fowl by the feet by a cord suspended from a hook or beam, and in thisposition stick and dry pick it. In some killing houses one man kills and rough picks, while one or two more remove the pin-feathers from the fowls he kills; in others each picker kills and picks clean his own birds. Some remark- 
able stories are told about rapid picking, but it is a good picker that picks clean 70 or 80 chickens a day.

56. Cooling Poultry. - As soon as a carcass is picked clean it should be put in cold water to cool. The quicker the animal heat is out of it, the better it will keep. Tubs, barrels or tanks should be used according to the quantity of poultry to be cooled, and unless arrangement is made for running water through whatever receptacles the poultry is cooled in the water should be frequently changed. The common practice is to put the carcass first in a barrel or vat, and after it has remained there for a quarter to half hour, or even longer, wash the blood from the mouth, clean the feet, and pass to another cooling barrel or tank.

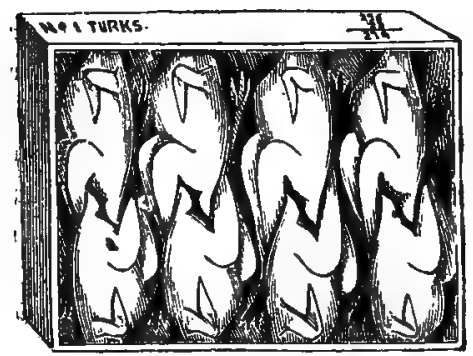

In cold weather carcasses cooled in water for from five or six to ten or twelve hours may then be taken from the water and hung up to dry - where they will not freeze. They are then ready to be packed the first thing in the morning. If it is very

Method of Packing Poultry in Boxes. warm, or if the carcasses exposed to the air would freeze, they should be kept in water until they are to be packed, then after having been allowed to drain for a few minutes they are - if packed dry - wiped dry before being packed. If to be iced they of course need not be dried off.

57. Packing Poultry for Shipment. - Poultry that does not require to be iced to preserve it while in transit is 
best packed in boxes. The illustration on page 94 shows the method of packing in boxes. The dimensions of the box to be used will depend on the size of stock and quantity to be shipped at one time. Boxes for roasters should be I 6 to 20 inches wide. For broilers they may be narrower, or one may use wide boxes, putting two rows of carcasses in each layer. When poultry has to be iced for shipment it is packed in barrels. A layer of broken ice is put in first, then a layer of poultry, then a layer of ice and a layer of poultry until the barrel is full. In packing poultry in barrels the packer begins his layer in the middle and packs heads down, backs up, and feet toward the center. After filling, the barrels are headed with burlap. This insures their being kept right side up.

58. Shipping.-Except in settled cold weather poultry should be shipped by express. The delays in freight shipments cause more risk of deterioration and shrinkage than it is wise to take. A shipper should not send shipments hit or miss at his convenience, but should find out all about the route his shipments must take, and arrange to have them en route as short a time as possible. Prompt delivery of goods means a great deal sometimes in the returns from them, and dressed poultry spoils so easily when exposed to bad conditions that wise shippers take no unnecessary chances. 
Adaptability of becels, 24 .

Anierican narket requilrements, 15. Appliances, miscellaneous, 55.

Beef seraps, 81.

jowel trouble. 66 .

I'roller, defined and descrfleed, 4.

liruoders, 35.

Isrooders, operating, 61 .

lircioding systems. 35 .

Buyjug eggs indiscriminately, $2:$.

Cabbage, 79.

('apunizing, 86.

C'ullal's for incubators, 37

C'lateral, $8 \%$.

Chicliens, hind of poultry marketed as, 4 .

Cold storage, effect of on denand, 10.

Coluny lookises, 52.

Color of broiller's, 15.

Combiniog broiler's and roastel's, 13.

combining bruler's with general poultry keeplug. 10.

Combiuing roasters with general poultry keeping, 12.

Combining roasters with other occupathon. 12.

Competition, 28.

conoled food. 67.

Cuok house, 54 .

Tooling poultry, 94

Crackef corv, 79

I)enınd and supply, 14 .

lomensiunt of fuecilialuf cellar, 40.

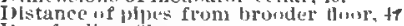

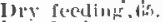

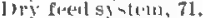

lory jickinis, :2.

Fign fur hilfching, 22. 57.

Finetrie lerulatols, $1,1$.

Exeluage hroller plants, 8 .

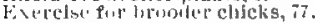

Fattening broilers, $k$.

Fattening roasters, st

Faults of breeding stock, 18.

Feeding ment. 80 .

Feeding systems, 65 .

Feeding systems lu pructlet, 7 th

Green cut bone, 81 .

tircen food, 79 .

(ivit, b2.

linwers producing their own thy

I Iammonton, broiler growlng at, 7 .

Iitching with hens, 32 .

Hialcr pit, 45 .

Huters, 46 .

Hut wealler, fattening in, 90 .

Hollses for growtng stork, 5l.

If mw often and how much to peet, is.

leing poultry for slipmeut, 95.

Int'ubators, 93.

Incubators in outbuldiugw, $\$ 1$.
Incubators, operatïn. 58.

Individual brouder's, 36

Individual lirooulers in long houses, 48 .

Individual brooder's in sinali liouses, 49.

Johunycake, 67.

Killing, methouls of, 92.

Killiar roum, 就。

Kind of stock for roasters, 19.

Land, purifying, 30 .

Land, quautity aud kind, 29.

Leglourns. 26 .

Light Brabmas, 25.

Lucal dena ods, 28.

Location, 27.

Markets, 27.

Masli feeding, $t b$.

Yash, receipts for, 69.

Methods of hafcling and rearing, 31.

ililk, 8:.

slongrel stock, 20.

Nursery broolers, 49.

Operating iscubators, 58.

Uruingtons, 24.

Outdour brouders, 50.

Uvercruwding, 63 .

Packing poultry, 94.

Packlng 1.00m, 55.

Ploking, methods of, 92 .

Pin-feathers, lark on broilers, 16

Pipe brovier lowses 41.

Pifl. - s stem of broding, 36.

Plimouth liocks, 24.

l'uinty of a good broiler. 15.

Pinilis uf a groud roaster, $1 \%$.

Prepured foods. 74.

Ruralator for bromers, hl.

Rointer, defined and teseribes, $T$.

Ryu lor gretn foud, Ni.

Sand for flour 4 , 4 .

Scalding poultry 9 ?

Selling joultry alive, 91.

Shipping, 95.

Soft roasters, 11.

South shore clichen- 11 .

Sinuth Shore nethods, 4 .

Spring latchel roastirs,

Souab hroller, 4.

Stinct for prudutefng bruilers, 17.

Supply and demand. it.

Temperature of hoodr $r, 62$.

Fentilating incubator ctllar, 60.

Water, 82 .

Wulghts of brollers, 4 .

IV thights of rodsters, $i$.

Wyandoties, 24.

Yellow legs and skin, 15, 19. 


